Check for updates

Cite this: J. Mater. Chem. A, 2019, 7, 21854

Received 3rd June 2019

Accepted 19th August 2019

DOI: $10.1039 / c 9 t a 05908 c$

rsc.li/materials-a

\title{
Oxygen exchange kinetics on systematically doped ceria: a pulsed isotope exchange study $\dagger$
}

\begin{abstract}
Maximilian Schaube, (D) Rotraut Merkle (D) * and Joachim Maier (D)
The importance of point defects for oxygen surface reaction kinetics on doped ceria is demonstrated by pulsed isotope exchange. The oxygen surface exchange reaction on 20 different $\mathrm{Gd} / \mathrm{Pr} / \mathrm{Tb}$, and $\mathrm{Nb}$ single and co-doped ceria samples is studied from $500-850{ }^{\circ} \mathrm{C}$ in $10-0.1 \% \mathrm{O}_{2}$ atmosphere. The highest rates are measured when both oxygen vacancies and redox-active centers are available. Gd-doping leads to exchange rates which are proportional to the concentrations of $\mathrm{Gd}$ and oxygen vacancies. $\mathrm{Pr}$ doped ceria exhibits a much stronger variation of the exchange rate - by almost five orders of magnitude from 0.6 to 20 mol\% Pr doping - emphasizing the importance of redox-active centers. The equilibrium exchange rates are low for $\mathrm{Nb}, \mathrm{Nb} / \mathrm{Pr}$, and $\mathrm{Nb} / \mathrm{Gd}$ co-doped ceria, emphasizing the important role of oxygen vacancies for oxygen dissociation and incorporation. The oxygen partial pressure dependence indicates that molecular oxygen species are involved in the rate-determining step (in addition to oxygen vacancies).
\end{abstract}

\section{Introduction}

Ceria $\left(\mathrm{CeO}_{2}\right)$ based materials find an extremely wide range of application, e.g., exhaust emission control and soot oxidation in automotive, catalyst for steam reforming, water gas shift and oxidation reactions, solid electrolyte in solid oxide fuel cells (SOFC) (see, e.g., ref. 1-6). Furthermore, ceria-based materials are also very well suited for fundamental investigations of surface kinetics (where the (111), (110) and (100) facets dominate the morphology) for several reasons: (i) simple cubic fluorite structure for undoped as well as doped ceria, (ii) only one cation site (in contrast to e.g., perovskites, avoiding complications from varying cation site occupation), (iii) intrinsic redox activity of Ce, (iv) perceptible mobility of oxygen vacancies as well as oxygen interstitials, (v) large solubility of acceptor, donor and redox-active dopants and (vi) wellunderstood bulk defect chemistry that allows tuning of point defect concentrations over a large range.

So far, isolated studies of the oxygen exchange kinetics were performed on $\mathrm{Gd}, \mathrm{Pr}, \mathrm{Tb}$, and $\mathrm{Nb}$ doped ceria by oxygen isotope exchange line profiling (IELP), ${ }^{7-13}$ isothermal isotope exchange (IIE), ${ }^{14}$ isotope exchange gas analysis (IEGA) ${ }^{15}$ pulsed isotope exchange (PIE), ${ }^{16,17}$ electrochemical impedance spectroscopy

Max Planck Institute for Solid State Research, Stuttgart, Germany. E-mail: r.merkle@ fkf.mpg.de

$\dagger$ Electronic supplementary information (ESI) available: The supplementary contains details of PIE quantification, a discussion of the $p\left(\mathrm{O}_{2}\right)$ dependence of surface defect concentrations, additional experimental data (lattice parameters, XRD pattern, SEM, EDX at grain boundaries, electrochemical impedance spectroscopy, isothermal isotope exchange, and exponential prefactors). See DOI: $10.1039 / \mathrm{c} 9$ ta05908c
(EIS) ${ }^{18,19}$ (ref. 19 refers to reducing conditions in $\mathrm{H}_{2}$ atmosphere), optical absorption spectroscopy, ${ }^{20,21}$ mass relaxation, ${ }^{22,23}$ and other methods. ${ }^{21,24,25}$

Regarding the reaction mechanism, experimental and $a b$ initio studies indicate that on reduced ceria, adsorbed superoxide and peroxide is formed easily, that adsorption of oxygen in an oxygen vacancy is energetically favorable, ${ }^{26-29}$ and that this occurs via superoxide and peroxide intermediates. Nevertheless, actual dissociation of molecular oxygen species is studied only rarely. The work in ref. 28 indicate that even for a superoxide adsorbed in an oxygen vacancy still a perceptible dissociation barrier must be overcome. Point defects such as oxygen vacancies or redox-active dopants naturally represent catalytically active centers for surface reactions (see, e.g., ref. 30-36).

It is obvious that oxygen vacancies and electronic dopants are required to carry out oxygen incorporation. But which of these defects limits the reaction depends on the materials classes and has yet to be clarified. This knowledge may then serve to purposefully tune the materials properties for application in e.g., electrochemical devices or as catalyst.

Surprisingly, to the knowledge of the authors there is no experimental study that systematically investigates the oxygen surface exchange reaction on a variety of doped ceria materials and an extended range of oxygen partial pressures by the same method and identical sample preparation to elucidate the influence of acceptor/donor and mixed valence dopants on the oxygen exchange kinetics and reaction mechanism. In particular, the present investigation covers a large dopant concentration range from $0.6-22 \mathrm{~mol} \%$ and allows for a direct comparison of dopants without and with redox-activity. The method of choice in the present study is pulsed isotope 
exchange: ${ }^{37}$ the sample is exposed to an isotope enriched oxygen pulse, and the resulting mixture of ${ }^{32} \mathrm{O}_{2},{ }^{16} \mathrm{O}^{18} \mathrm{O}$, and ${ }^{36} \mathrm{O}_{2}$ isotopologues quantified by mass spectroscopy. This technique enables a fast screening of the oxygen incorporation reaction rate as a function of dopant content and oxygen partial pressure in the absence of any precious metals, and yields additional mechanistic information compared to IELP. ${ }^{37-41}$

\section{Experimental}

\subsection{Sample preparation}

In this study, ceria samples with 0.6 to $22 \mathrm{~mol} \%$ of dopants are used and labelled by $x \mathrm{~A} y \mathrm{BDC}$ where $x$ and $y$ denote the content (in mol\%) of dopants A and B, and DC abbreviates "doped ceria". Single- and co-doped ceria was synthesized by a Pechini type approach ${ }^{42-44}$ using $\mathrm{Me}\left(\mathrm{NO}_{3}\right)_{3} \cdot \mathrm{H}_{2} \mathrm{O}$ (Me: Ce, $\mathrm{Gd}$, $\mathrm{Pr}$, or $\mathrm{Tb}$ ) (Reacton, Alfa Aesar, 99.99\%) and $\mathrm{NH}_{4} \mathrm{NbC}_{2} \mathrm{O}_{4} \cdot \mathrm{H}_{2} \mathrm{O}$ (Aldrich) in the desired molar ratios (the exact water content was determined by thermogravimetry). Citric acid (CA) (Roth, >99.5\%) and ethylene glycol (EG) (Emsure, Merck) were added to a solution of $60 \mathrm{~mL}$ distilled water and $87 \mathrm{mmol}$ metal salts with a few droplets of conc. $\mathrm{HNO}_{3}$ (Roth, p.a.) whereby the molar ratio of $\mathrm{EG} / \mathrm{CA}$ is two and for $\mathrm{EG} / \mathrm{Me}$ one. The mixture was stirred at $175{ }^{\circ} \mathrm{C}$ until a yellow resin was formed. After subsequent pyrolysis at $T \approx 250^{\circ} \mathrm{C}$ in the glass beaker, the obtained powder was homogenized by dry milling in a zirconia mill for $45 \mathrm{~min}$.

For pulsed isotope exchange, $1 \mathrm{~g}$ powder at a time was compacted into dense pellets by spark plasma sintering (SPS, FCT-DP D 5/2, FCT Systeme) at $1000^{\circ} \mathrm{C}$ for $3 \mathrm{~min}$ in a graphite mold with $10 \mathrm{~mm}$ diameter at $6 \mathrm{kN}$ pressure. The pellets were calcined at $800{ }^{\circ} \mathrm{C}$ for $8 \mathrm{~h}$ and annealed at $1400{ }^{\circ} \mathrm{C}$ for $8 \mathrm{~h}$ in air with a heating/cooling rate of $100{ }^{\circ} \mathrm{C} \mathrm{h}^{-1}$. Their density was determined using a $5 \mathrm{~mL}$ pycnometer with water as solvent. The pellets were crushed and sieved to a particle size between 60 and $100 \mu \mathrm{m}$, and fired again at $1400{ }^{\circ} \mathrm{C}$ for $8 \mathrm{~h}$ with $100^{\circ} \mathrm{C} \mathrm{h}^{-1}$ in air. The resulting particles showed a smooth surface (Fig. 2 in ESI $\dagger$ ) and the particle size did not change.

\subsection{Sample characterization}

Phase purity and lattice parameters were examined by X-ray diffraction (Panalytical Empyrean) with $\mathrm{Cu} \mathrm{K} \alpha$ radiation (40 $\mathrm{kW}, 40 \mathrm{~mA}$ ) in Bragg-Brentano reflection geometry. The cation stoichiometry was checked by inductively coupled plasma optical emission spectroscopy (Spectro Ciros CCD, Spectro Analytical Instruments). The morphology of the particle surface was investigated by scanning electron microscopy (Merlin Gemini II, Carl Zeiss). BET surface area measurements were conducted by POROTEC GmbH (Thermo Scientific Surfer) using krypton as adsorption gas. Surface segregation of dopants was investigated by X-ray photoelectron spectroscopy (Kratos AXIS Ultra) with monochromatized $\mathrm{Al} \mathrm{K} \alpha$ with a base pressure $<10^{-10}$ mbar. Spectra were obtained with analyzer pass energy of $20 \mathrm{eV}$ and the analysis was performed with CasaXPS. Under the applied measurement conditions, a surface layer of approximately $4.5 \mathrm{~nm}$ thickness is probed. ${ }^{45}$ Segregation effects to grain boundaries were investigated by transmission electron microscopy (TEM) and energy-dispersive X-ray spectroscopy (EDX) with an ARM 200CF (JEOL) and a Centurio EDX detector (200 kV, probe size $1.2 \AA$ ). Thermogravimetry (TG, STA 449 C, Netzsch) of the oxygen non-stoichiometry of PDC was performed on powder samples $(\approx 0.5 \mathrm{~g})$ with oxygen partial pressure ranging between

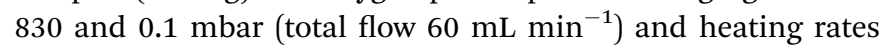
between $2{ }^{\circ} \mathrm{C} \mathrm{min}{ }^{-1}$ (high $T$ and $p\left(\mathrm{O}_{2}\right)$ ) and $0.1^{\circ} \mathrm{C} \mathrm{min}^{-1}$ (small $T$ and $\left.p\left(\mathrm{O}_{2}\right)\right)$ to ensure equilibration. Buoyancy correction was done by using a measurement of an empty $\mathrm{Al}_{2} \mathrm{O}_{3}$ crucible. The absolute value of $\mathrm{O}$ stoichiometry was obtained by assuming that the plateau at high $T$ and low $p\left(\mathrm{O}_{2}\right)$ corresponds to all $\mathrm{Pr}$ in $3+$ oxidation state.

\subsection{Pulsed isotope exchange (PIE)}

Pulsed isotope exchange $\mathrm{e}^{17,37-39,41,46}$ was conducted in a vertical $\mathrm{Al}_{2} \mathrm{O}_{3}$ micro plug flow reactor (inner diameter $2 \mathrm{~mm}$, length 300 $\mathrm{mm}$, Friatec AG) loaded with $100 \mathrm{mg}$ of sample particles, which were fixed by a $15 \mathrm{mg}$ quartz wool plug. The bed height was always approximately $8 \mathrm{~mm}$. The carrier gas - mixtures of $10 \%$, $1 \%$ or $0.1 \% \mathrm{O}_{2}$ in $\mathrm{N}_{2}$ - enters the reactor at the top, with a flow

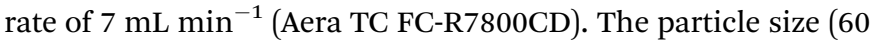
to $100 \mu \mathrm{m}$ ) and flow rate were chosen to keep the pressure drop across the packed bed below $20 \%$. Prior to isotope exchange, the particles in the reactor were pre-treated by flushing with the appropriate carrier gas at $900{ }^{\circ} \mathrm{C}$ for $30 \mathrm{~min}$ with a heating and cooling rate of $2.5^{\circ} \mathrm{C} \mathrm{min}{ }^{-1}$. An $0.5 \mathrm{~mL}$ injection loop was used to introduce an ${ }^{18} \mathrm{O}$ enriched pulse of 10,1 or $0.1 \% \mathrm{O}_{2}$ mixed from 97 at\% enriched ${ }^{18} \mathrm{O}$ gas (Euriso-top) and 98 at $\%$ enriched ${ }^{15} \mathrm{~N}$ gas (Westfalen; in order to recognize the gas from the pulse loop and as internal standard) into the system by switching a 6way-valve. At each measurement temperature the sample was equilibrated for $30 \mathrm{~min}$ in the carrier gas stream prior to isotope exchange pulses. The pulses were repeated three times with three minutes in-between. The pulse response was monitored by a quadrupole mass spectrometer (Balzers Prisma QME200, Pfeiffer Vacuum) at the exit of the reactor at $m / z=30\left({ }^{15} \mathrm{~N}_{2}\right), 32$ $\left({ }^{16} \mathrm{O}_{2}\right), 34\left({ }^{18} \mathrm{O}^{16} \mathrm{O}\right)$ and $36\left({ }^{18} \mathrm{O}_{2}\right)$ with a resolution of five points per second. The quantification of oxygen isotopologues in the gas phase was achieved by normalizing the corresponding peak areas to the integrated signal of ${ }^{15} \mathrm{~N}_{2}$ (see ESI $\dagger$ for more information).

\section{Theory}

\subsection{Bulk defect chemistry}

The overall oxygen incorporation into the bulk material can be expressed by

$$
\mathrm{O}_{2}+2 \mathrm{~V}_{\mathrm{O}}^{* *} \rightleftharpoons 2 \mathrm{O}_{\mathrm{O}}^{\times}+4 \mathrm{~h}^{\cdot}
$$

written in Kröger-Vink notation ${ }^{47}$ where $\mathrm{V}_{\mathrm{O}}^{*}$ indicates oxygen vacancies, $\mathrm{O}_{\mathrm{O}}^{\times}$lattice oxygen, and $\mathrm{h}{ }^{\bullet}$ holes. The defect concentrations are determined by a mass action constant

$$
K(T)=\frac{\left[\mathrm{O}_{\mathrm{O}}^{\times}\right]^{2}\left[\mathrm{~h}^{*}\right]^{4}}{p\left(\mathrm{O}_{2}\right)\left[\mathrm{V}_{\mathrm{O}}^{*}\right]^{2}}
$$


where square brackets denote concentrations. Ideally dilute behavior is assumed in the following considerations. Due to its intrinsic redox-activity, already undoped ceria $\mathrm{CeO}_{2-\delta}$ shows oxygen deficiency at elevated temperatures according to

$$
\mathrm{O}_{\mathrm{O}}^{\times} \rightleftharpoons 2 \mathrm{e}^{\prime}+\mathrm{V}_{\mathrm{O}}^{\ddot{*}}+\frac{1}{2} \mathrm{O}_{2}
$$

where the electrons $\mathrm{e}^{\prime}$ are reducing $\mathrm{Ce}^{4+}\left(\mathrm{Ce}_{\mathrm{Ce}}^{\times}\right)$to $\mathrm{Ce}^{3+}\left(\mathrm{Ce}_{\mathrm{Ce}}^{\prime}\right)$ forming small polarons ( $c f$. ref. 48). Typical values of $\delta$ at $800{ }^{\circ} \mathrm{C}$ range between $10^{-5}\left(1\right.$ bar $\left.\mathrm{O}_{2}\right)$ and $0.1\left(10^{-20}\right.$ bar $\left.\mathrm{O}_{2}\right) \cdot{ }^{49}$ In this intrinsic regime, the electroneutrality condition is $2\left[\mathrm{~V}_{\mathrm{O}}^{* *}\right]=\left[\mathrm{e}^{\prime}\right]$, and the oxygen partial pressure dependence of $\mathrm{V}_{\mathrm{O}}^{\cdot *}$ and $\mathrm{e}^{\prime}\left(\mathrm{Ce}_{\mathrm{Ce}}^{\prime}\right)$ is $2\left[\mathrm{~V}_{\mathrm{O}}^{*}\right]=\left[\mathrm{e}^{\prime}\right] \propto p\left(\mathrm{O}_{2}\right)^{1 / 6}$. Doping allows one to deliberately change the defect concentrations.

Oxygen vacancies can also be introduced by doping with an acceptor of fixed valence such as $\mathrm{Gd}^{3+}$, yielding an oxide ion conducting electrolyte material (see, e.g., ref. 50-52):

$$
\mathrm{Gd}_{2} \mathrm{O}_{3}+2 \mathrm{Ce}_{\mathrm{Ce}}^{\times}+\mathrm{O}_{\mathrm{O}}^{\times} \rightarrow 2 \mathrm{Gd}_{\mathrm{Ce}}^{\prime}+\mathrm{V}_{\mathrm{O}}^{*}+2 \mathrm{CeO}_{2}
$$

The amount of $\mathrm{V}_{\mathrm{O}}^{*}$ is fixed according to $\left[\mathrm{Gd}_{\mathrm{Ce}}^{\prime}\right]=2\left[\mathrm{~V}_{\mathrm{O}}^{*}\right]$, and the oxygen partial pressure dependency in this case is found to be $\pm 1 / 4$ for holes $\left(\mathrm{O}_{\mathrm{O}}^{\circ}\right)$ and excess electrons $\left(\mathrm{Ce}_{\mathrm{Ce}}^{\prime}\right)$. It is important to note that $\mathrm{V}_{\mathrm{O}}^{*}$ created via such acceptor doping do not lead to an enhanced conduction electron concentration (rather to an increased hole concentration owing to the equilibrium in eqn (1)). Since they can incorporate oxide ions, $\mathrm{V}_{\mathrm{O}}^{*}$ represent acidic centers $^{31}$ (rather than Lewis basic centers as suggested in ref. 33).

Donor doping, e.g., by $\mathrm{Nb}^{5+}$, leads to suppression of $\mathrm{V}_{\mathrm{O}}^{*}$ and formation of oxygen interstitials under oxidizing conditions,

$$
\mathrm{Nb}_{2} \mathrm{O}_{5}+2 \mathrm{Ce}_{\mathrm{Ce}}^{\times} \rightarrow 2 \mathrm{Nb}_{\mathrm{Ce}}^{\cdot}+\mathrm{O}_{\mathrm{i}}^{\prime \prime}+2 \mathrm{CeO}_{2} \quad\left[\mathrm{Nb}_{\mathrm{Ce}}^{\cdot}\right]=2\left[\mathrm{O}_{\mathrm{i}}^{\prime \prime}\right]
$$

and electronic compensation by electrons $\left(\mathrm{Ce}_{\mathrm{Ce}}^{\prime}\right)$ under reducing conditions ${ }^{13,53,54}$

$$
\mathrm{Nb}_{2} \mathrm{O}_{5}+4 \mathrm{Ce}_{\mathrm{Ce}}^{\times} \rightarrow 2 \mathrm{Nb}_{\mathrm{Ce}}^{\cdot}+2 \mathrm{Ce}_{\mathrm{Ce}}^{\prime}+2 \mathrm{CeO}_{2}\left[\mathrm{Nb}_{\mathrm{Ce}}^{\cdot}\right]=\left[\mathrm{Ce}_{\mathrm{Ce}}^{\prime}\right]
$$

In the temperature and oxygen partial pressure regime probed by PIE, both defect compensations (5) and (6) occur simultaneously, ${ }^{54}$ but oxygen interstitials are the dominating defects. ${ }^{53}$ The solubility limit of $\mathrm{Nb}$ in ceria was found to be $3 \mathrm{~mol} \% .^{55}$ For acceptor-donor co-doped materials with equal dopant concentration, $\left(\left[\mathrm{Nb}_{\mathrm{Ce}}^{\circ}\right]=\left[\mathrm{Ac}_{\mathrm{Ce}}^{\prime}\right]\right)$ the oxygen defect concentration is minute.

Praseodymium- as well as terbium-doped ceria show similar defect chemistry ${ }^{56}$ and much stronger redox activity compared to Ce. Thus the intrinsic incorporation reaction (1) is complemented by a redox reaction, e.g., in the case of Pr:

$$
\mathrm{O}_{2}+2 \mathrm{~V}_{\mathrm{O}}^{*}+4 \mathrm{Pr}_{\mathrm{Ce}}^{\prime} \rightleftharpoons 2 \mathrm{O}_{\mathrm{O}}^{\times}+4 \mathrm{Pr}_{\mathrm{Ce}}^{\times}
$$

Such a deep acceptor situation involves electronic and ionic defects. A high amount of Pr-doping introduces increased electronic conductivity due to small polaron hopping between $\mathrm{Pr}^{3+} / \mathrm{Pr}^{4+}$ and $\mathrm{Ce}^{4+}$, making this material a mixed electronic and ionic conductor (MIEC).$^{\mathbf{1 8 , 4 2 , 5 7 , 5 8}}$ Fig. 1 shows the $\mathrm{Pr}_{\mathrm{Ce}}^{\prime}$ concentration for 2, 6 and 20PDC calculated from TG measurements according to eqn (7). In the regime of $\left[\mathrm{Pr}_{\mathrm{Ce}}^{\times}\right]>\left[\mathrm{Pr}_{\mathrm{Ce}}^{\prime}\right]$, the electroneutrality condition is $\left[\mathrm{Pr}_{\mathrm{Ce}}^{\prime}\right]=2\left[\mathrm{~V}_{\mathrm{O}}^{* *}\right]$, and both concentrations scale with $p\left(\mathrm{O}_{2}\right)^{-1 / 6}$. At higher $T$ and/or lower $p\left(\mathrm{O}_{2}\right)$, the dependence flattens and $\left[\mathrm{Pr}_{\mathrm{Ce}}^{\prime}\right] \rightarrow[\mathrm{Pr}]_{\text {tot }}$. Under the conditions of the PIE experiment (blue shaded area in Fig. 1), about $15-60 \%$ of the Pr is in the $3+$ state, and a corresponding $\mathrm{V}_{\mathrm{O}}^{*}$ concentration is present. The actual $\left[\mathrm{Pr}_{\mathrm{Ce}}^{\prime}\right] /[\mathrm{Pr}]_{\text {tot }}$ ratio varies a bit with $p\left(\mathrm{O}_{2}\right)$ and $T$, but the dependence on $[\mathrm{Pr}]_{\text {tot }}$ is small. Thus, overall the relation $\left[\mathrm{V}_{\mathrm{O}}^{*}\right] \propto[\mathrm{Pr}]_{\text {tot }}$ is a reasonably good approximation to describe the variation of $\left[\mathrm{V}_{\mathrm{O}}^{*}\right]$ with $[\mathrm{Pr}]_{\text {tot }}$, which varies by 1.5 orders of magnitude between the lowest and highest doped samples.

\subsection{Surface orientation and surface defect concentrations}

The defect concentrations that are relevant for the oxygen exchange reaction are those in the surface layer. The most stable termination of $\mathrm{CeO}_{2}$ is (111), followed by (110) and (100). ${ }^{59}$ No surface energies for doped ceria could be retrieved, but at least for low dopant concentrations the same sequence of surface stabilities is highly probable. Since the particles used for PIE in the present investigation have been annealed at $1400{ }^{\circ} \mathrm{C}$, it is reasonable to assume that the surface has largely reconstructed
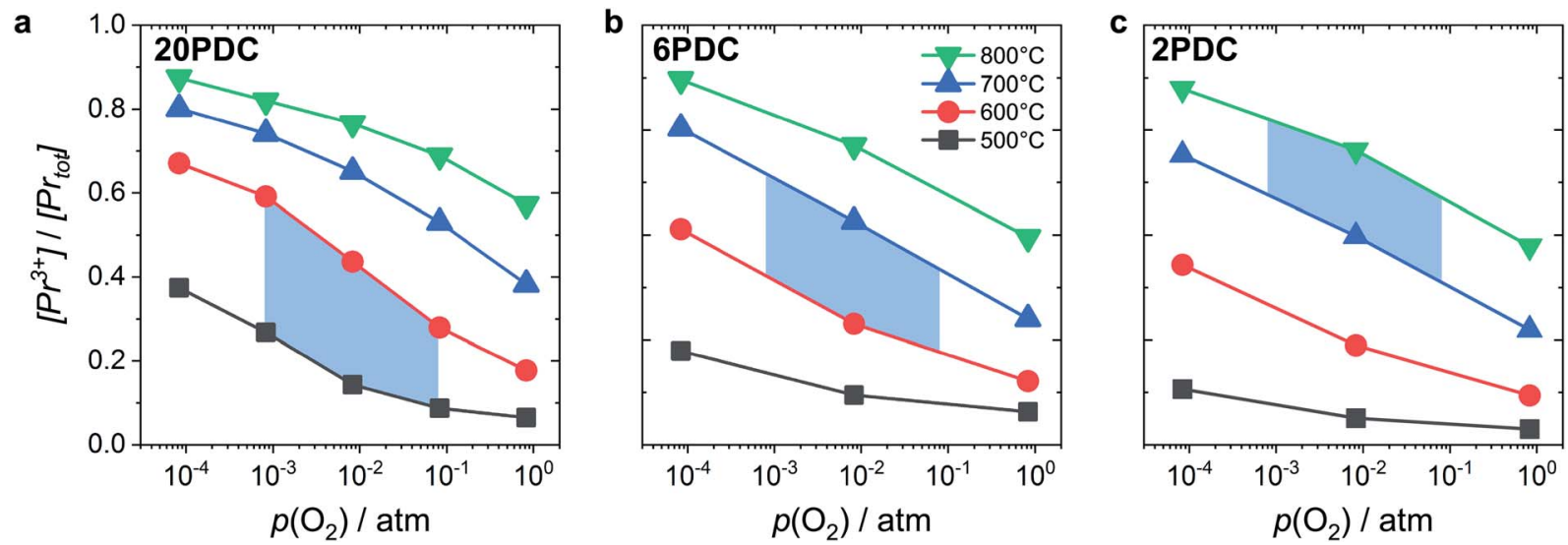

Fig. 1 Ratio of $\mathrm{Pr}^{3+}$ relative to total Pr content as a function of oxygen partial pressure at different temperatures for 20PDC (a), 6PDC (b), and 2PDC (c). The blue shaded area indicates the typical conditions for the PIE measurements. 
into the most stable terminations (in terms of free energy), yielding a similar distribution for undoped as well as doped samples. While under reducing conditions the dependence of the $\mathrm{V}_{\mathrm{O}}^{*}$ formation energy $\left(\Delta H_{\mathrm{red}}^{0}\right)$ on the surface orientation is expected to lead to significantly different $\mathrm{V}_{\mathrm{O}}^{*}$ concentrations for the different surfaces, ${ }^{59,60}$ such differences are expected to be much less pronounced for acceptor doped samples where $\left[\mathrm{V}_{\mathrm{O}}^{*}\right]$ is largely fixed by the dopant concentration. Measurements of the orientation dependence of surface exchange rates are scarce. The challenges are, amongst others, the discrimination from strain effects and the fact that thermodynamically unstable surfaces must be prevented from reconstruction under the experimental conditions at elevated $T$ (in turn, hypothetically very active but highly unstable surfaces will not contribute in a typical oxygen exchange experiment because they reconstruct). For epitaxial $\mathrm{La}_{0.7} \mathrm{Sr}_{0.3} \mathrm{MnO}_{3-\delta}$ perovskite films, the variation of surface rate constant between (001), (110), and (111) surface orientations has been found to be less than a factor of four. ${ }^{61,62}$

Since the surface represents a severe structural distortion, the absolute defect concentrations differ from the respective bulk values. Typically it is expected that, owing to the smaller number of bonds to cations to be broken, $\mathrm{V}_{\mathrm{O}}^{*}$ form thermodynamically more easily in the surface layer of an oxide. This is supported by DFT calculations, which yield a decreased $\mathrm{V}_{\mathrm{O}}^{*}$ formation energy in the surface layer of ceria depending on the exposed facets, where $\Delta H_{\text {red }}^{0}$ increases in the order $(110)<(100)$ $<$ (111). ${ }^{60}$ Additionally, an excess surface charge and a subsurface space charge layer may appear. As long as the type of the majority carrier does not change relative to bulk and the surface charge (if present) is approximately $p\left(\mathrm{O}_{2}\right)$ independent, the $p\left(\mathrm{O}_{2}\right)$ dependence of the defects will be the same in bulk and surface layer.

Direct measurements of surface defect concentrations (preferably under conditions of well-defined $T$ and $p\left(\mathrm{O}_{2}\right)$ ) are very challenging, thus only few data are available. For ceriabased materials, the following three observations have to be considered:

(i) For nanosized undoped ceria powder or ceramic samples, modified $p\left(\mathrm{O}_{2}\right)$ dependencies for oxygen deficiency and/or ntype conductivity were found, which have been interpreted by pronounced defect association of $\mathrm{e}^{\prime}$ with $\mathrm{V}_{\mathrm{O}}^{*}$ (which is equivalent to a less than doubly charged oxygen vacancy). ${ }^{63-65}$

(ii) For thin films of undoped and Sm-doped ceria in strongly reducing atmosphere, ambient-pressure XPS indicated strongly enhanced surface $\mathrm{V}_{\mathrm{O}}^{* *}$ and $\mathrm{Ce}_{\mathrm{Ce}}^{\prime}\left(\mathrm{e}^{\prime}\right)$ concentrations and correspondingly modified $p\left(\mathrm{O}_{2}\right)$ dependencies. ${ }^{66-68}$

(iii) For a PDC thin film on a YSZ substrate, $\left[\mathrm{Pr}_{\mathrm{Ce}}^{\prime}\right]$ at the surface was measured by ambient-pressure XPS while the effective $p\left(\mathrm{O}_{2}\right)$ was tuned by a d.c. bias, and an increased surface $\left[\mathrm{Pr}_{\mathrm{Ce}}^{\prime}\right]$ with decreased $p\left(\mathrm{O}_{2}\right)$ dependence was found. ${ }^{69}$

The relevance of observation (i) with modified defect charge caused by electron trapping in the oxygen vacancies is considered to be small for the present study; the acceptor doping leads to a high oxygen vacancy and low conduction electron concentration, so association cannot significantly alter the average oxygen valence state. The measurements of undoped and Sm- doped films in case (ii) yield strongly increased surface oxygen vacancy and $\mathrm{Ce}_{\mathrm{Ce}}^{\prime}$ concentrations compared to bulk (in strongly reducing conditions), from which a decreased ceria reduction enthalpy by $1 \mathrm{eV}$ was deduced. Such a decrease agrees well with earlier findings from DFT (decrease by $0.8 \mathrm{eV}$ for (111) surface to $1.4 \mathrm{eV}$ for (110) surface; ${ }^{60}$ and experiments on nanocrystalline ceria samples. ${ }^{70}$ Despite the more increased surface vacancy concentration, the excess $\mathrm{V}_{\mathrm{O}}^{*}$ and $\mathrm{Ce}_{\mathrm{Ce}}^{\prime}$ concentrations match almost exactly, so the charge of the surface layer is rather small. ${ }^{71}$ For comparably high $p\left(\mathrm{O}_{2}\right)$ of $10^{-4}$ bar at $450{ }^{\circ} \mathrm{C}$, the surface concentration of $\mathrm{Ce}_{\mathrm{Ce}}^{\prime}$ remains very low, ${ }^{71}$ much smaller than the acceptor concentrations used in the present work. Thus, we can reasonably assume that for the present GDC samples, bulk and surface layer are in the same defect chemical regime, with $\mathrm{V}_{\mathrm{O}}^{*}$ and $\mathrm{Gd}_{\mathrm{Ce}}^{\prime}$ as majority defects. Based on this, a similar $p\left(\mathrm{O}_{2}\right)$ dependence of the minority defect species $\mathrm{Ce}_{\mathrm{Ce}}^{\prime}$ is expected in the present work as in GDC bulk, but with increased absolute values (at $700{ }^{\circ} \mathrm{C}$, a decrease of $\Delta H_{\text {red }}^{0}$ by $1 \mathrm{eV}$ corresponds to an increase of $\left[\mathrm{Ce}_{\mathrm{Ce}}^{\prime}\right]$ by a factor of approx. 400). Finding (iii), is not too surprising, since $\operatorname{Pr}$ is more easily reduced than Ce. However, the observation of a modified $p\left(\mathrm{O}_{2}\right)$ dependence even under conditions where $\left[\mathrm{Pr}_{\mathrm{Ce}}^{\prime}\right]$ is relatively small remains unexplained in ref. 69.

In the ESI $\dagger$ we discuss in more detail specific situations that can occur at the surface, and we derive the possible oxygen partial pressure dependences. Overall we conclude that in the present experimental conditions for GDC the surface $\mathrm{V}_{\mathrm{O}}^{*}$ concentration is largely determined by the $\mathrm{Gd}_{\mathrm{Ce}}^{\prime}$ acceptor doping, and the $p\left(\mathrm{O}_{2}\right)$ dependence of minority $\mathrm{Ce}_{\mathrm{Ce}}^{\prime}$ species is similar as in bulk. PDC might exhibit a smaller $p\left(\mathrm{O}_{2}\right)$ dependence of $\mathrm{Pr}_{\mathrm{Ce}}^{\prime}$ in the range of 0.1 instead of 1/6.

\subsection{Calculation of reaction rates}

During PIE measurements, the sample is in equilibrium with the gas phase $p\left(\mathrm{O}_{2}\right)$, therefore the forward and back reaction rates of the oxygen exchange reaction are equal and characterized by the equilibrium exchange rate $\Re_{0} \cdot{ }^{72,73}$ In the PIE experiment, $\Re_{0}$ can be obtained from the isotope fraction before and after the reactor according to ref. 37 .

$$
\frac{\mathrm{d}^{18} f_{\mathrm{g}}}{\mathrm{d} t}=-\frac{\Re_{0} S}{2 n_{\mathrm{O}_{2}}}\left({ }^{18} f_{\mathrm{g}}-{ }^{18} f_{\mathrm{lat}}\right) \Leftrightarrow \Re_{0}=\frac{2 n_{\mathrm{O}_{2}}}{\tau S} \ln \left(\frac{{ }^{18} f_{\mathrm{g}, \mathrm{i}}}{{ }^{18} f_{\mathrm{g}, \mathrm{e}}}\right)
$$

The surface area of the particles is denoted by $S, n_{\mathrm{O}_{2}}$ is the molar amount of oxygen in the gas phase, $t$ denotes time, and ${ }^{18} f_{\mathrm{g}, \mathrm{i}}$ and ${ }^{18} f_{\mathrm{g}, \mathrm{e}}$ are the gas phase fraction of ${ }^{18} \mathrm{O}$ in the pulse at the inlet $\left(97\right.$ at $\left.\%{ }^{18} \mathrm{O}\right)$ and exit of the reactor (calculated according to ${ }^{18} f={ }^{36} f+0.5^{34} f$ where ${ }^{36} f$ and ${ }^{34} f$ are the fractions of ${ }^{36} \mathrm{O}_{2}$ and ${ }^{34} \mathrm{O}_{2}$ in the gas phase). The mean residence time $\tau$ in the reactor was calculated with $\tau=V / \nu$ ( $V$ is the gas phase volume in the reactor and $\nu$ the volume flow rate of oxygen passing through the reactor). $\Re_{0}$ has the unit of oxygen atoms per time and area and is related to the effective rate constant of the surface exchange reaction $k^{*}\left[\mathrm{~cm} \mathrm{~s}^{-1}\right]$ by $^{39}$

$$
\Re_{0}=k^{*}\left[\mathrm{O}_{\mathrm{O}}^{\times}\right]
$$


(the concentration of regular oxide ions is to a good approximation constant over the covered $T, p\left(\mathrm{O}_{2}\right)$ range, thus $\Re_{0}$ and $k^{*}$ exhibit the same $p\left(\mathrm{O}_{2}\right)$ dependence). In the derivation of eqn (8), it is assumed that the concentration of ${ }^{18} \mathrm{O}$ in the surface layer of the sample is negligible. This is fulfilled when bulk diffusion in the particle is fast compared to surface exchange, and the number of ${ }^{18} \mathrm{O}$ atoms in the pulse is small compared to the total number of oxygen atoms in the particles.

This analysis of $\Re_{0}$ does not require the assumption of a specific reaction mechanism. From the variation of $\Re_{0}$ with $p\left(\mathrm{O}_{2}\right)$ and dopant/defect concentrations several important conclusions can be drawn. If a dissociative-adsorption reaction is rate-determining, that reaction determines the overall exchange rate $\Re_{0}$. For example, the oxygen incorporation may be determined by the rate of dissociative-adsorption (eqn (10), with a fast oxygen adsorption as a pre-equilibrium) which involves electronic defects. Due to microscopic reversibility principle, close to equilibrium the forward and backward reactions must have identical overall dependences on $p\left(\mathrm{O}_{2}\right)$ and point defect concentrations. It suffices to analyze just the forward rate:

$$
\mathrm{O}_{2} \underset{\overleftarrow{k}_{\mathrm{da}}}{\stackrel{\vec{k}_{\mathrm{da}}}{\rightleftharpoons}} 2 \mathrm{O}_{\mathrm{ad}}{ }^{-}+2 \mathrm{~h}^{\cdot} \Rightarrow \Re_{0} \approx \vec{k}_{\mathrm{da}} p\left(\mathrm{O}_{2}\right)^{1} \Rightarrow \Re_{0} \propto p\left(\mathrm{O}_{2}\right)^{1-m}
$$

The exponent $m$ denotes the influence of point defects on the overall oxygen partial pressure exponent $n$. Since molecular oxygen is involved, $\Re_{0}$ is proportional to $p\left(\mathrm{O}_{2}\right)^{n}$ with $n \leq 1$. The exponent $n$ can be lowered to $1-m$ through the influence of point defects as exemplified in section 3 of the ESI, $\dagger$ e.g., if [ $\left.\mathrm{h}^{\bullet}\right]$ $\propto p\left(\mathrm{O}_{2}\right)^{1 / 4}$ in case of GDC appear before the actual rate-determining elementary step (rds). A different $p\left(\mathrm{O}_{2}\right)$ dependence can be obtained if instead incorporation of a single oxygen ad-atom is the rds (see eqn (12)). Then for the equilibrated dissociativeadsorption reaction, one can write the mass action law:

$$
K_{\mathrm{da}}=\frac{\left[\mathrm{O}_{\mathrm{ad}}{ }^{-}\right]^{2}\left[\mathrm{~h}^{\cdot}\right]^{2}}{p\left(\mathrm{O}_{2}\right)}
$$

The overall exchange rate $\Re_{0}$ equals the rate of oxygen adatom incorporation. By considering eqn (11), one obtains that $\Re_{0}$ is proportional to $p\left(\mathrm{O}_{2}\right)^{n}$ with $n \leq 0.5$ :

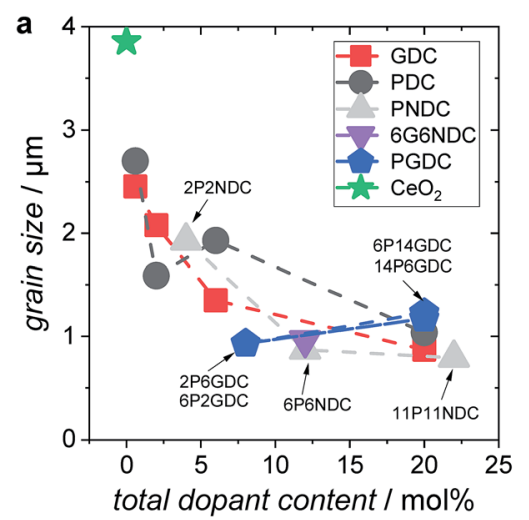

$$
\begin{aligned}
\mathrm{O}_{\mathrm{ad}}{ }^{-}+\mathrm{V}_{\mathrm{O}} \underset{\overleftarrow{k}_{\mathrm{i}}}{\stackrel{\vec{k}_{\mathrm{i}}}{\rightleftharpoons}} \mathrm{O}_{\mathrm{O}}^{\times}+\mathrm{h} & \Rightarrow \Re_{0} \approx \frac{\vec{k}_{\mathrm{i}} \sqrt{K_{\mathrm{da}}}\left[\mathrm{V}_{\mathrm{O}}^{*}\right]}{[\mathrm{h}]} \sqrt{p\left(\mathrm{O}_{2}\right)} \\
& \Rightarrow \Re_{0} \propto p\left(\mathrm{O}_{2}\right)^{0.5-m}
\end{aligned}
$$

This concept is generally applicable and enables one to distinguish whether molecular or atomic oxygen is involved in the rds. We assume here ideal behavior; non-idealities might nevertheless be present at high dopant concentrations. However, sufficient quantitative data are lacking, and the effect on the $p\left(\mathrm{O}_{2}\right)$ dependence of $\Re_{0}$ is expected to be rather modest.

\section{Results}

\subsection{Sample characterization}

The SPS pellets showed densities between 95 and $98 \%$ of the theoretical value. The surface of the grains appears smooth without apparent porosity (ESI Fig. $2 \dagger$ ). The mean grain size ranges from 1 to $4 \mu \mathrm{m}$, decreasing with increased doping concentration (Fig. 2a). The BET surface area of the $60-100 \mu \mathrm{m}$ particles was measured to be $0.014 \mathrm{~m}^{2} \mathrm{~g}^{-1}$.

XRD measurements on doped ceria particles confirmed a phase pure, cubic fluorite type crystal lattice (lattice parameters in ESI $\dagger$ ). For Gd-doped ceria, the lattice parameter follows Vegard's law, ${ }^{74}$ indicating a solid solution with an increase corresponding to the larger ion radius of $\mathrm{Gd}^{3+}\left(\mathrm{Ce}^{4+} 0.97 \AA\right.$, $\mathrm{Gd}^{3+}$ $1.053 \AA)^{75}$ (Fig. 2b). The slight decrease of the lattice constant for PDC indicates that the average Pr oxidation state is closer to 4+ rather than $3+$ in the as-prepared samples $\left(\operatorname{Pr}^{4+} 0.96 \AA, \operatorname{Pr}^{3+}\right.$ $1.126 \AA)^{75}$ which is in accordance with the TG data in Fig. 1 and with defect model calculations. ${ }^{57}$

XPS measurements on 6GDC, 20GDC, 6PDC, 20PDC, and 6P6NDC (Fig. 3) revealed a moderate accumulation of dopants at the particle's surface of up to $30 \%$ relative to bulk values after the second annealing step at $1400{ }^{\circ} \mathrm{C}$. The strength of the dopant segregation increases according to [Gd $]<[\mathrm{Pr}]<[\mathrm{Nb}]$. TEM/EDX analysis on 6PDC particles indicated also a Pr accumulation at the grain boundaries which is stronger than for the surface (ESI $\dagger$ ).

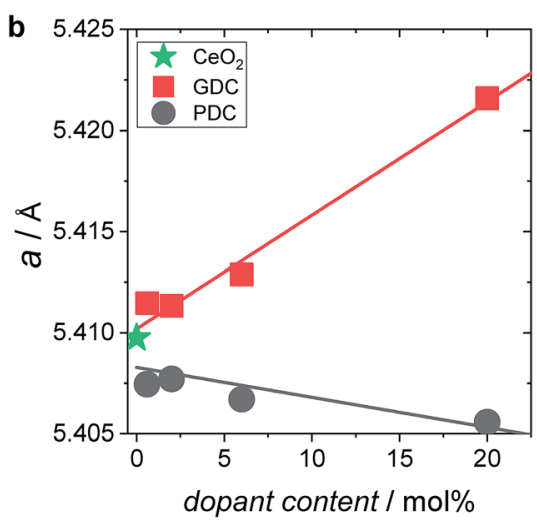

Fig. 2 (a) Grain size of doped ceria samples as function of total dopant content. (b) Lattice parameter a as function of dopant content. 


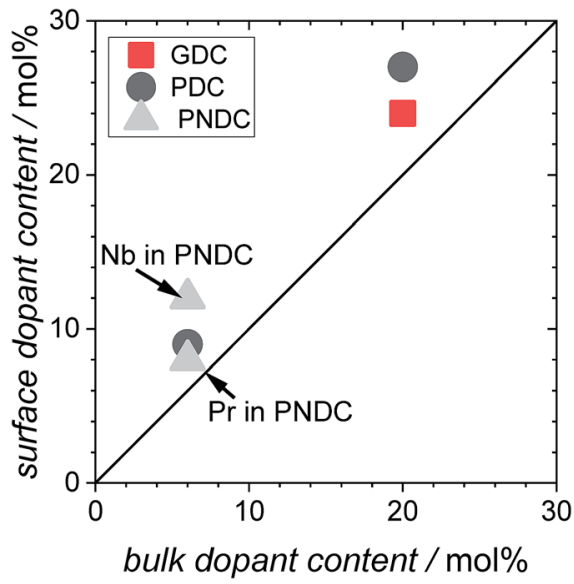

Fig. 3 Dopant content at the surface of the PIE particles (double annealed at $1400{ }^{\circ} \mathrm{C}$ ) plotted against the nominal dopant concentration.

\subsection{Pulsed isotope exchange}

For all samples, the regime which was probed by PIE measurements is considered to be surface controlled. The characteristic lengths $l_{0}=k^{*} / D^{*}\left(D^{*}=\right.$ oxygen tracer diffusion coefficient, $k^{*}=$ effective tracer exchange rate constant) calculated with data from ref. 8, 9 and 18 are typically 10-1000 times larger than the mean particle radius, which means that the concentration gradient of ${ }^{18} \mathrm{O}$ inside the particles vanishes and the bulk diffusion does not affect the ${ }^{18} \mathrm{O}$ exchange kinetics. ${ }^{76}$ Grain boundaries in acceptor-doped ceria are known to exhibit moderately blocking behavior for oxide ion diffusion, but in the temperature regime of the present PIE experiments, the blocking effect becomes small ${ }^{77,78}$ (see also conductivity data from impedance spectroscopy in the $\mathrm{ESI} \dagger$ ).

In Fig. 4 the fractions of the molecular oxygen isotopologues in the pulse, measured at the exit of the packed bed reactor, are plotted against the reactor temperature. With increasing temperature, ${ }^{18} \mathrm{O}$ starts to incorporate into the sample indicated by a decrease of ${ }^{36} f$. Due to the fact that the oxygen stoichiometry is in equilibrium, the same amount of ${ }^{16} \mathrm{O}$ needs to be released from the sample in the form of ${ }^{32} \mathrm{O}_{2}$ or ${ }^{34} \mathrm{O}_{2}$ depending on the underlying reaction mechanism.

Results obtained at temperatures above $800{ }^{\circ} \mathrm{C}$ should be interpreted with care, since in this regime the $\mathrm{Al}_{2} \mathrm{O}_{3}$ reactor itself showed oxygen exchange activity (Fig. 4, close symbols), mainly by isotopic scrambling at the surface as indicated by the high ${ }^{34} \mathrm{O}_{2}$ fraction. Negative mole fractions for ${ }^{32} \mathrm{O}_{2}$ originate from some unavoidable smearing of the ${ }^{18} \mathrm{O}$ pulse: at the edges of the pulse, residual ${ }^{32} \mathrm{O}_{2}$ can scramble at the reactor surface with ${ }^{36} \mathrm{O}_{2}$ yielding ${ }^{34} \mathrm{O}_{2}$, as indicated by peak splitting of the ${ }^{34} \mathrm{O}_{2}$ MS signal. Undoped $\mathrm{CeO}_{2}$ (Fig. 4, green symbols) showed similar low oxygen exchange activity as the empty $\mathrm{Al}_{2} \mathrm{O}_{3}$ reactor. Thus, for undoped ceria and 2NDC no activation energies are given and only an upper limit of $\Re_{0}$ can be indicated in Fig. 7.

All Gd or Pr/Tb single- and co-doped ceria samples measured in this study are more active for oxygen exchange than undoped $\mathrm{CeO}_{2}$. On 0.6GDC the oxygen incorporation begins at around $750{ }^{\circ} \mathrm{C}$. This onset temperature shifts to lower values with increasing [Gd], so that for 20GDC the incorporation commences already at $600{ }^{\circ} \mathrm{C}$. All GDC samples show a pronounced formation of ${ }^{34} \mathrm{O}_{2}$, which points to a slow incorporation reaction rate relative to the rates of oxygen adsorption and dissociation.
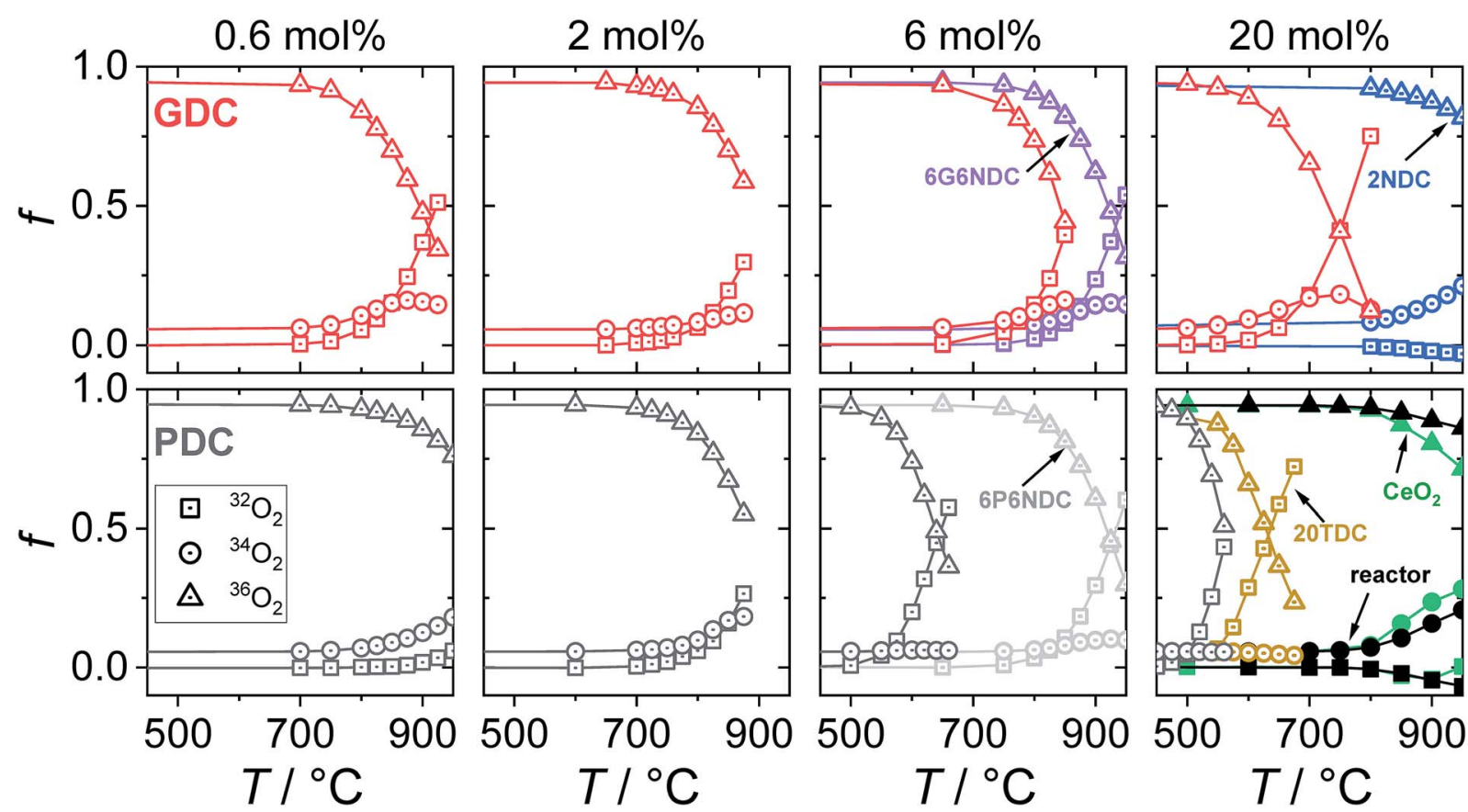

Fig. 4 Molar oxygen isotopologues fractions $(f)$ measured by mass spectrometry on the gas exiting the reactor; all measurements in $10 \%$ O atmosphere. 

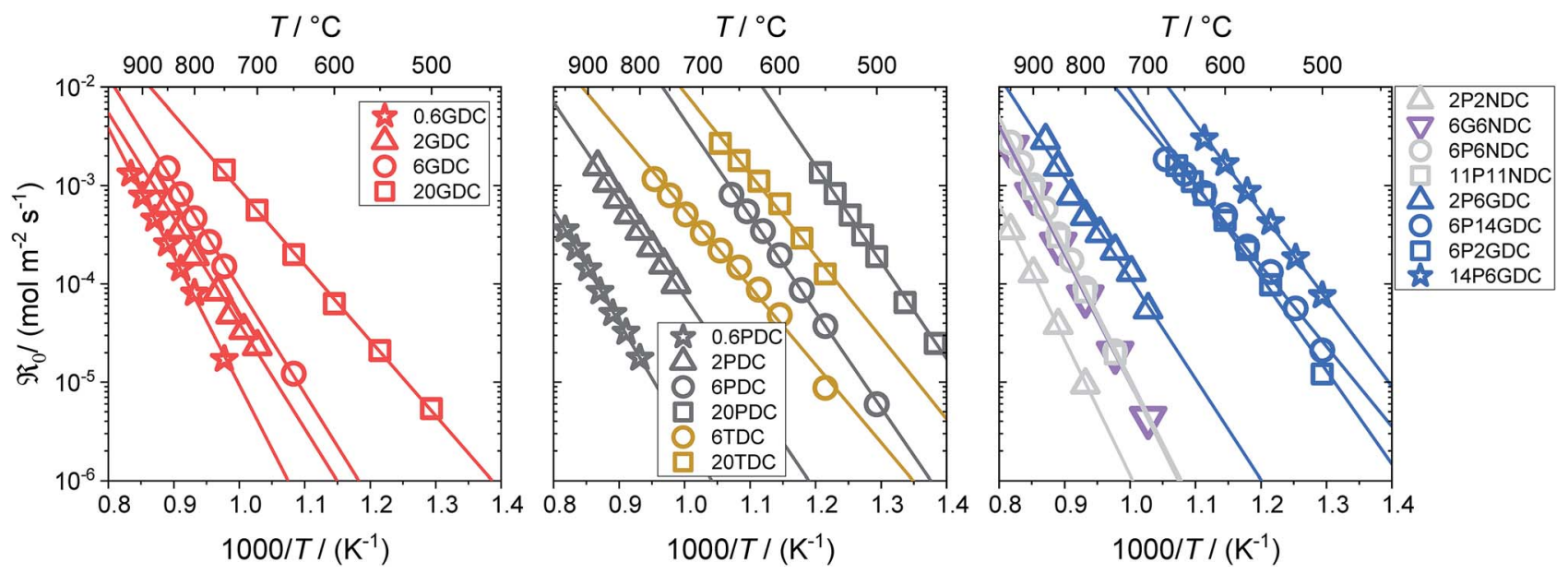

Fig. 5 Temperature dependence of the equilibrium exchange rate $\Re_{0}$ for doped ceria samples, measured in $10 \% \mathrm{O}_{2}$.

The increase of the exchange activity on PDC samples is even more pronounced than on GDC. On 20PDC, oxygen incorporation was observed already at $500{ }^{\circ} \mathrm{C}$. On 0.6PDC the conversion at high $T$ is in the same low range as for undoped $\mathrm{CeO}_{2}$ and the empty reactor. The onset of perceptible oxygen conversion quickly shifty to lower $T$ for higher Pr dopant contents. The absence of ${ }^{34} \mathrm{O}_{2}$ at $>2 \mathrm{~mol} \%$ Pr or Tb suggests that dissociated oxygen species incorporate faster into the bulk compared to GDC with similar dopant content.

2NDC and co-doped 6P6NDC/6G6NDC were less active compared to GDC and PDC/TDC samples. Furthermore, the formation of ${ }^{34} \mathrm{O}_{2}$ on PNDC was less distinct than for GNDC. Since $\mathrm{Nb}$ as donor dopant decreases the oxygen vacancy concentration or may even lead to oxygen interstitials, these results show that oxygen vacancies are crucial for the oxygen exchange reaction.

\subsection{Analysis of the ${ }^{18} \mathrm{O}$ gas phase fraction}

From the measured overall isotope fractions ${ }^{18} f_{\mathrm{g}, \mathrm{i}}$ and ${ }^{18} f_{\mathrm{g}, \mathrm{e}}$ in the gas phase, the equilibrium exchange rates are calculated by

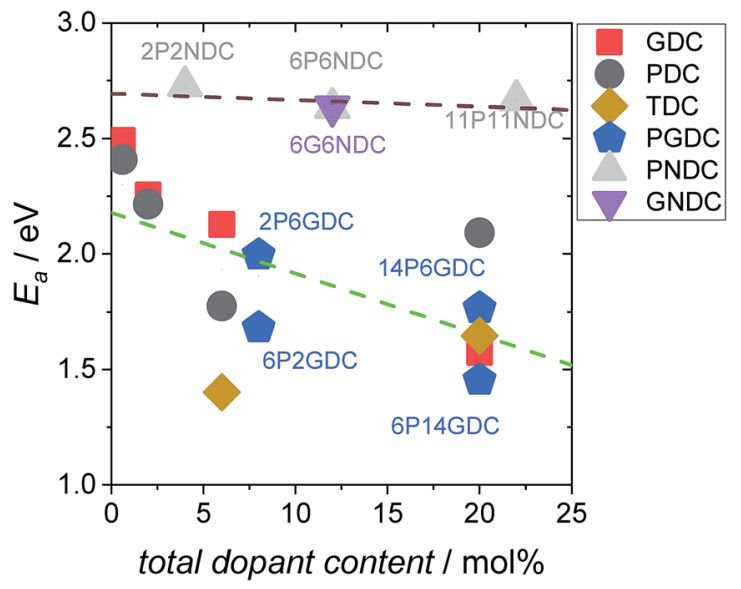

Fig. 6 Activation energies calculated from the temperature dependence of the equilibrium exchange rate $\Re_{0}$, in $10 \% \mathrm{O}_{2}$. eqn (8). According to Fig. 5, the temperature dependencies of $\Re_{0}$ follow Arrhenius behavior. Fig. 6 presents the extracted activation energies which range between 1.4-2.8 eV. Two distinct groups can be recognized: singly $\mathrm{Pr} / \mathrm{Tb}$ and $\mathrm{Gd}$ doped ceria as well as $\mathrm{Pr} / \mathrm{Gd}$ co-doped ceria showed $E_{\text {a }}$ values ranging between 1.5-2.3 eV, while $\mathrm{Nb}$ doping led to high activation energies between 2.5 and $2.8 \mathrm{eV}$. Furthermore, with increasing total dopant concentration $E_{\mathrm{a}}$ tends to decrease slightly. However, since the measured $E_{\mathrm{a}}$ is a combination of the actual reaction barrier of the rds and the reaction enthalpies of fast preceding steps, the interpretation of this trend is not straightforward. The consistently higher $E_{\mathrm{a}}$ for the $\mathrm{Nb}$ co-doped samples might possibly arise from higher reaction barriers in absence of a high inherent $\left[\mathrm{V}_{\mathrm{O}}^{*}\right]$, or from a higher effective $T$-dependence of the $\mathrm{V}_{\mathrm{O}}^{*}$ concentration than in PDC/TDC and GDC. It is interesting to note that while the prefactor of $\Re_{0}$ varies only moderately between $2 \%$ and $20 \%$ doping for the GDC samples, the increase of $\Re_{0}$ with increasing $[\mathrm{Pr}]_{\text {tot }}$ is largely caused by an increased prefactor.

The trends of oxygen exchange rate with dopant type and concentration can best be compared at a fixed temperature $\left(700{ }^{\circ} \mathrm{C}\right)$, as shown in Fig. 7. Since undoped $\mathrm{CeO}_{2}$ showed similar low oxygen exchange activity as the empty $\mathrm{Al}_{2} \mathrm{O}_{3}$ reactor no activation energies are given and only an upper limit of $\Re_{0}$ can be indicated in Fig. 7 .

For GDC the condition $[\mathrm{Gd}]=2\left[\mathrm{~V}_{\mathrm{O}}^{*}\right]$ holds for the bulk. For the vacancy concentration at the surface, different absolute values but still an approximate proportionality to the bulk Gd concentration is expected (see Section 3.1). Fig. 7a shows that the exchange rate is approximately proportional to the bulk $\mathrm{V}_{\mathrm{O}}^{*}$ concentration $\Re_{0} \propto\left[\mathrm{V}_{\mathrm{O}}^{*}\right]^{1}$. This strongly indicates that one $\mathrm{V}_{\mathrm{O}}^{*}$ is involved before or in the rds step of the oxygen exchange reaction. The importance of $\mathrm{V}_{\mathrm{O}}^{*}$ for the water splitting reaction on ceria has recently been emphasized by XPS measurements under near-ambient conditions. ${ }^{68}$

In contrast, for PDC $\Re_{0}$ increases more strongly according to $\Re_{0} \propto[\mathrm{Pr}]^{3.5}$ (Fig. 7b), which overall increases $\Re_{0}$ by almost 5 orders of magnitude relative to undoped ceria. Since rather 

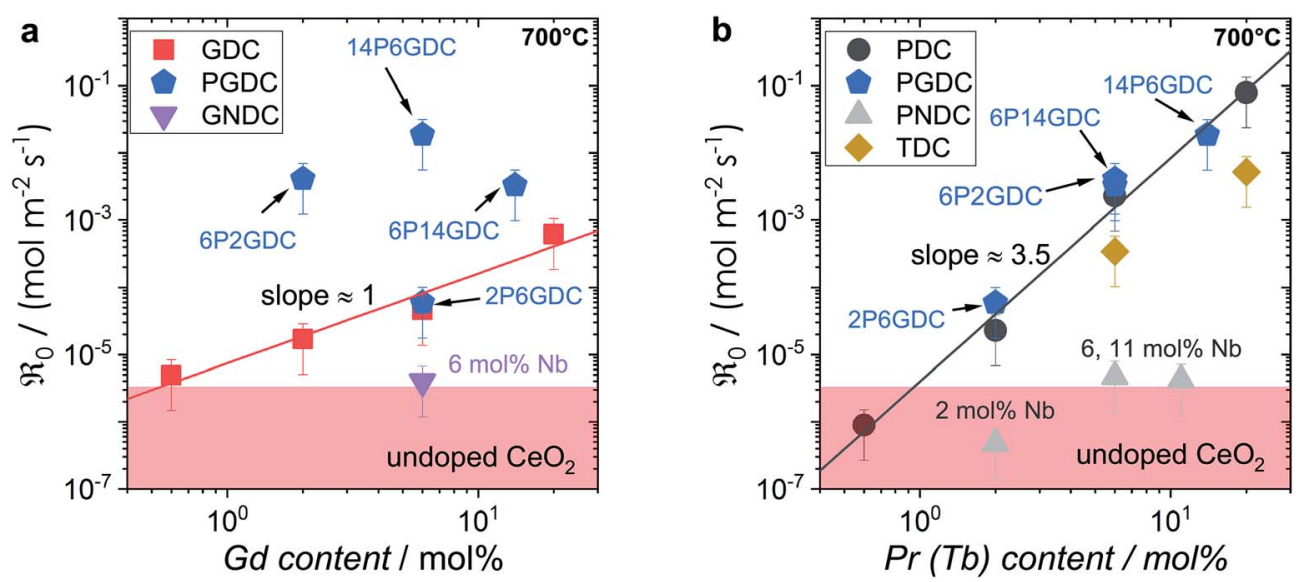

Fig. $7 \Re_{0}$ as a function of bulk (a) Gd and (b) Pr content (values measured in $10 \%$ oxygen atmosphere and inter/extrapolated to $700{ }^{\circ} \mathrm{C}$ ). The shaded area indicates the activity range of undoped ceria and 2NDC. Values for 06GDC, 20GDC, 06PDC, 2PDC, 6PDC and 20PDC are mean values calculated from at least two measurements.

extensive extrapolations are required to obtain $\Re_{0}$ values for all PDC samples at one common $T$, the numerical value of this slope might carry some uncertainty. Nevertheless, such a strong dependence on Pr content suggests that in addition to the increased $\mathrm{V}_{\mathrm{O}}^{*}$ concentration (despite the mixed $\mathrm{Pr}^{3+} / \mathrm{Pr}^{4+}$ valence, $\left[\mathrm{V}_{\mathrm{O}}^{*}\right]$ is roughly proportional to the overall $\operatorname{Pr}$ content, see Section 3.1), the inherent redox activity of $\mathrm{Pr}^{3+} / \mathrm{Pr}^{4+}$ itself also affects the exchange rate. Despite a small offset, TDC shows a similar strong increase of $\Re_{0}$, indicating that redox-active dopants tend to activate the oxygen incorporation. This is in line with several observations in literature that mixed conducting fluorites or perovskites exhibit faster oxygen exchange than purely ionic or electronic conductors. ${ }^{38,79-84}$

Similar trends as for the singly Gd or Pr doped samples are also found for Gd and Pr co-doped samples. While additional Gd doping of PDC samples (Fig. 7b) has almost no effect, Pr codoping of GDC perceptibly increases $\Re_{0}$ (Fig. 7a). Nb co-doping with $\mathrm{Nb}$ concentration matching that of $\mathrm{Gd}$ or Pr leads to exchange rates that are in the region of undoped ceria. This strongly supports the assignment that the rate increases with increasing $[\mathrm{Gd}]$ is related to the increased $\left[\mathrm{V}_{\mathrm{O}}^{*}\right]$ and not to some specific effect of the Gd cations.

Further important information on the reaction mechanism is obtained from measurements of $\Re_{0}$ as function of oxygen partial pressure (Fig. 8). For all samples in the present study, the exponents $n$ for the $p\left(\mathrm{O}_{2}\right)$ dependence are always above $1 / 2$. As discussed in Section 3.3, this means that molecular oxygen species are involved in the rds of oxygen incorporation.

Let us summarize the key experimental observations regarding the oxygen exchange mechanism:

(i) On GDC, $\Re_{0} \propto[\mathrm{Gd}]^{1} \propto\left[\mathrm{V}_{\mathrm{O}}^{*}\right]^{1}$ and on PDC $\Re_{0} \propto[\mathrm{Pr}]^{3.5}$ (with $\left.[\operatorname{Pr}] \propto\left[\mathrm{V}_{\mathrm{O}}^{*}\right]\right)$, which indicates that at least one $\mathrm{V}_{\mathrm{O}}^{*}$ is involved in or before the rds.

(ii) For both systems $\Re_{0} \propto p\left(\mathrm{O}_{2}\right)^{>1 / 2}$ therefore, molecular oxygen species are involved in the rds.
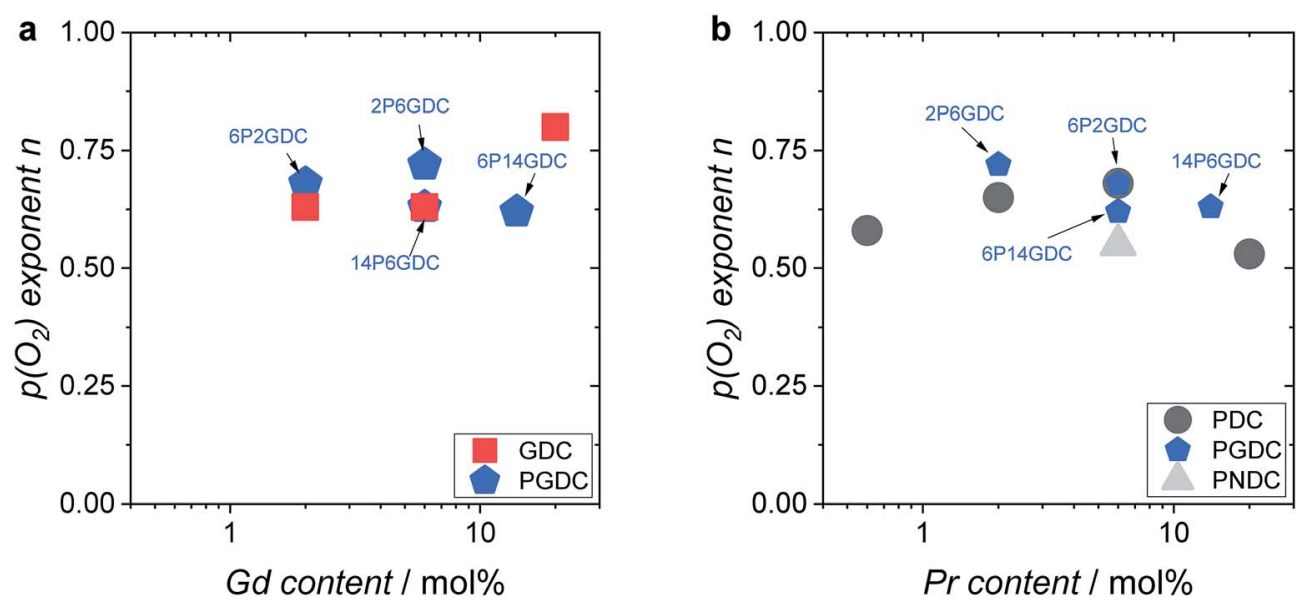

Fig. 8 Oxygen partial pressure exponent $n$ as function of (a) $\mathrm{Gd}$ and (b) Pr content. Measurement temperatures: $2 \mathrm{GDC} 810{ }^{\circ} \mathrm{C}, 6 \mathrm{GDC} 785^{\circ} \mathrm{C}$, $20 \mathrm{GDC} 625^{\circ} \mathrm{C}, 2 \mathrm{PDC} 800^{\circ} \mathrm{C}, 6 \mathrm{PDC} 650^{\circ} \mathrm{C}, 2 \mathrm{PPDC} 560^{\circ} \mathrm{C}, 2 \mathrm{P} 6 \mathrm{GDC} 775^{\circ} \mathrm{C}, 6 \mathrm{P} 2 \mathrm{GDC}, 6 \mathrm{P} 14 \mathrm{GDC} 600^{\circ} \mathrm{C}, 14 \mathrm{P} 6 \mathrm{GDC} 575^{\circ} \mathrm{C}, 2 \mathrm{P} 2 \mathrm{NDC} 850{ }^{\circ} \mathrm{C}$. The relative error for the exponents are sampler than the symbols. 


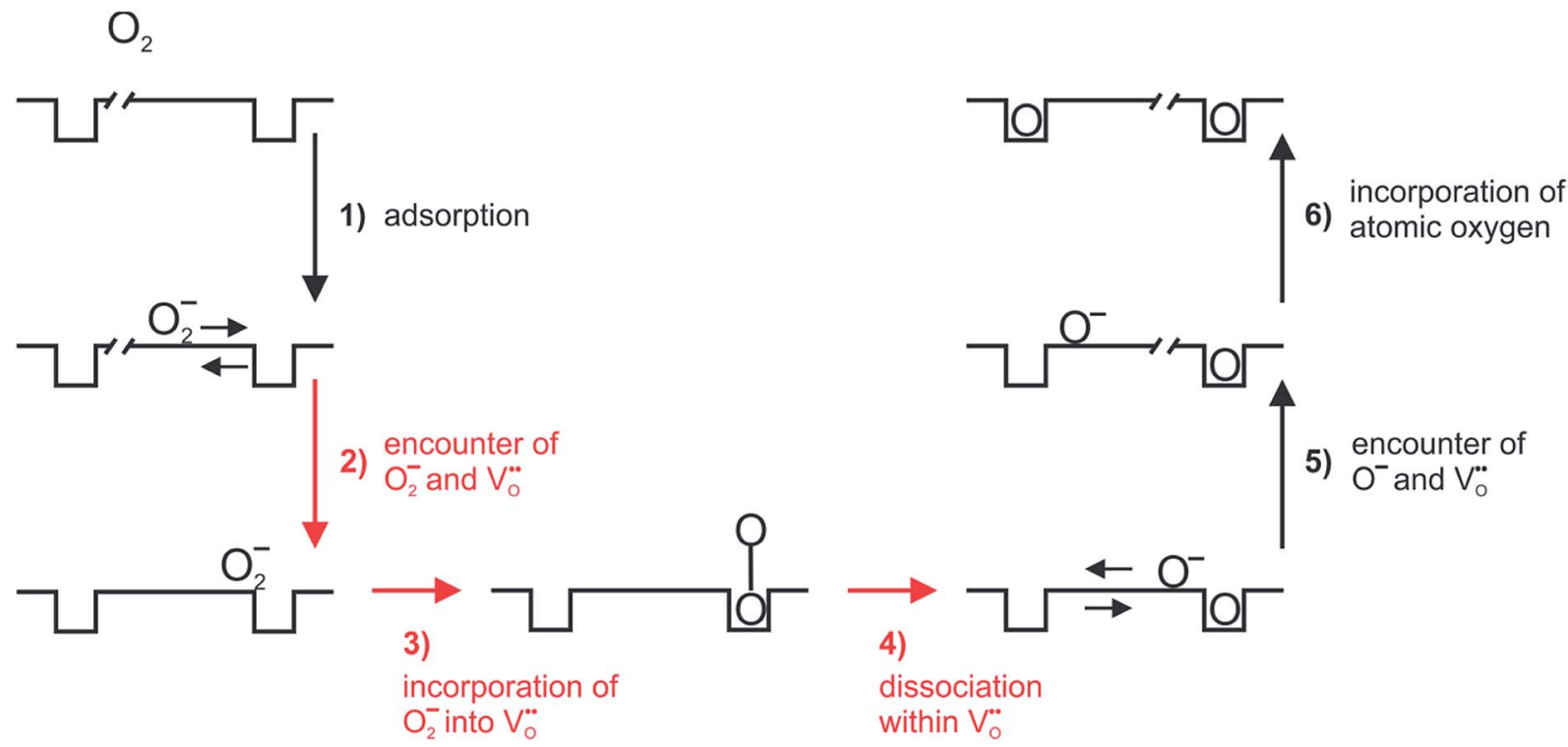

Fig. 9 Plausible reaction mechanism of oxygen exchange for GDC. The rate-determining step is expected to be within steps 2-4. The encounter in step 2 can occur by migration of $\mathrm{O}_{2}{ }^{-}$and/or $\mathrm{V}_{\mathrm{O}}^{*}$ along the surface. The charges of the oxygen intermediates cannot be directly concluded; they are tentatively assigned.

(iii) The fact that the exponent of the overall $p\left(\mathrm{O}_{2}\right)$ dependencies is below one indicates that defects with negative $p\left(\mathrm{O}_{2}\right)$ dependency are involved.

Based on this we can suggest for GDC the following mechanism depicted in Fig. 9 which is consistent with the measured data. From the observation that in addition to molecular oxygen species also $\mathrm{V}_{\mathrm{O}}^{*}$ are involved in/before the rds, the dissociation without $\mathrm{V}_{\mathrm{O}}^{*}$ is most likely ruled out as a possible reaction mechanism for GDC as well as for PDC.

Adsorption including a first electron transfer is expected to be fast, since such chemisorption processes occur already at room temperature or below (see, e.g., ref. 26, 29 and 85). For reduced ceria $^{26}$ and redox-active perovskites such as (La,Sr) $\mathrm{MnO}_{3 \pm \delta}$ superoxide as well as peroxide species are formed. ${ }^{86}$ However, the latter are regarded as less probable for GDC (which has a large bandgap) under oxidizing conditions. On pre-reduced $\mathrm{CeO}_{2}$ nanocrystals, at $173 \mathrm{~K}$ a concentration of adsorbed molecular oxygen species of about $2-3 \mu \mathrm{mol} \mathrm{O}_{2}$ per $\mathrm{m}^{2}$ was found (corresponding to surface coverage of about $6 \%$ ), ${ }^{29}$ but at the higher $T$ and $p\left(\mathrm{O}_{2}\right)$ of the PIE experiment significantly lower values are expected.

For perovskites ${ }^{87}$ as well as for ceria, ${ }^{28}$ DFT calculations indicate that the dissociation of molecular oxygen species is facilitated when it is first incorporated into an oxygen vacancy. Thus we consider oxygen exchange to proceed via an encounter of $\mathrm{O}_{2}{ }^{-}$and $\mathrm{V}_{\mathrm{O}}^{*}$ (step 2; at this stage we cannot distinguish which of these species migrates towards the other), incorporation of $\mathrm{O}_{2}{ }^{-}$into the $\mathrm{V}_{\mathrm{O}}^{*}$ (step 3), and actual dissociation (step 4). For perovskites such as (La,Sr) $\mathrm{MnO}_{3 \pm \delta}$ or $\mathrm{Ba}_{0.5} \mathrm{Sr}_{0.5} \mathrm{Co}_{0.8} \mathrm{Fe}_{0.2} \mathrm{O}_{3-\delta}$ there is evidence that rather a surface oxygen vacancy approaches the adsorbed oxygen species than vice versa. ${ }^{\mathbf{0 0}, 87}$

On the basis of the present experimental data, one of steps 24 is rate-determining. Since the overall $p\left(\mathrm{O}_{2}\right)$ dependence indicates molecular oxygen species in the rds, the encounter of $\mathrm{O}^{-}$and $\mathrm{V}_{\mathrm{O}}^{*}$ in step 5 cannot be limiting. This implies that either the concentration of atomic oxygen is higher than that of $\mathrm{O}_{2}{ }^{-}$ (as observed for ( $\mathrm{La}, \mathrm{Sr}) \mathrm{MnO}_{3 \pm \delta}{ }^{87}$ leading to a shorter diffusion length to $\mathrm{V}_{\mathrm{O}}^{*}$ ), or that the mobile species is the adsorbed oxygen with a higher surface mobility for $\mathrm{O}^{-}$compared to $\mathrm{O}_{2}{ }^{-}$. The fact that the incorporation of oxygen into $\mathrm{V}_{\mathrm{O}}^{*}$ (step 6) is not the rds may indicate that also the similar step 3 is not limiting. The charges of the oxygen intermediates cannot be directly concluded from the measured $p\left(\mathrm{O}_{2}\right)$ and $\left[\mathrm{V}_{\mathrm{O}}^{*}\right]$ dependences, they are tentatively assigned (in particular for adsorbed atomic $\mathrm{O}$ species the charge may also depend on the actual surface termination).

The overall $p\left(\mathrm{O}_{2}\right)$ dependence of $\Re_{0}$ contains also contributions from the involved point defects (a detailed deviation is found in the ESI $\dagger$ ). Assuming that just one hole is involved in the fast pre-equilibrium in eqn (13) before the rds, one obtains for $\Re_{0}$ :

$$
\begin{aligned}
& \mathrm{O}_{2} \underset{\vec{k}_{1}}{\stackrel{\vec{k}_{1}}{\rightleftharpoons}} \mathrm{O}_{2}^{-}+\mathrm{h}^{\cdot} \quad \text { with } K_{1}=\frac{\left[\mathrm{O}_{2}^{-}\right]\left[\mathrm{h}^{*}\right]}{p\left(\mathrm{O}_{2}\right)} \\
& \Re_{0}=\vec{k}_{2}\left[\mathrm{O}_{2}^{-}\right]\left[\mathrm{V}_{\mathrm{O}}^{*}\right]=\vec{k}_{2} K_{1} p\left(\mathrm{O}_{2}\right)\left[\mathrm{V}_{\mathrm{O}}^{*}\right]\left[\mathrm{h}^{*}\right]^{-1}
\end{aligned}
$$

For GDC with fixed $\mathrm{V}_{\mathrm{O}}^{*}$ concentration, [h"] $\propto p\left(\mathrm{O}_{2}\right)^{1 / 4}$ holds in the bulk, which yields $\Re_{0} \propto p\left(\mathrm{O}_{2}\right)^{3 / 4}$. This fits well to the measured overall $p\left(\mathrm{O}_{2}\right)$ dependence showing an exponent of $0.6-0.8$. From these values it follows that in addition to one $\mathrm{V}_{\mathrm{O}}^{*}$, at least one electron is consumed or one hole is produced before or in the rds. Regarding the dependence of $\Re_{0}$ on $\left[\mathrm{V}_{\mathrm{O}}^{*}\right]$, one has to consider that the hole concentration depends on $\left[\mathrm{V}_{\mathrm{O}}^{*}\right]$ by eqn (2) according to $\left[\mathrm{h}^{*}\right] \propto\left[\mathrm{V}_{\mathrm{O}}^{*}\right]^{1 / 2}$, resulting in $\Re_{0} \propto\left[\mathrm{V}_{\mathrm{O}}^{*}\right]^{1 / 2}$, in contrast to the measured $\Re_{0} \propto[\mathrm{Gd}] \propto\left[\mathrm{V}_{\mathrm{O}}^{*}\right]$ relation for GDC. A 
tentative consideration to resolve this discrepancy is that $\left[\mathrm{h}^{*}\right] \propto\left[\mathrm{V}_{\mathrm{O}}^{* *}\right]^{1 / 2}$ enters the rate expression as a consequence of the chemisorption equilibrium in eqn (13). If the system behaved ideally, $K_{1}$ would be independent of $[\mathrm{Gd}]$ and $\left[\mathrm{V}_{\mathrm{O}}^{*}\right]$, but $\left[\mathrm{O}_{2}^{-}\right]$ would decrease with increasing $[\mathrm{Gd}]$ and $\left[\mathrm{V}_{\mathrm{O}}^{*}\right]$. However, the decreased effective cation charge with increasing Gd content might make the $\mathrm{O}_{2}$ chemisorption increasingly favorable (deviation from ideal behavior) such that overall the $\mathrm{O}_{2}{ }^{-}$ concentration becomes approximately independent of $\left[\mathrm{V}_{\mathrm{O}}^{*}\right]$. Alternative mechanisms with two $\mathrm{V}_{\mathrm{O}}^{*}$ involved before or in the rds (leading to stronger [ $\left.\mathrm{V}_{\mathrm{O}}^{*}\right]$ dependencies of $\Re_{0}$ ) are considered less probable as they require the encounter of adsorbed oxygen with two $\mathrm{V}_{\mathrm{O}}^{*}$.

A striking feature for PDC is that $\Re_{0}$ increases overproportionally with $[\mathrm{Pr}]$. It is reasonable to assume that a part of the dependence originates in one $\mathrm{V}_{\mathrm{O}}^{*}$ involved before/in the rds (as was found for GDC) which yields a contribution of $\Re_{0} \propto\left[\mathrm{V}_{\mathrm{O}}^{*}\right] \propto[\mathrm{Pr}]$. The remaining dependence suggests a direct involvement of the redox couple $\mathrm{Pr}^{3+} / \mathrm{Pr}^{4+}$ in the oxygen exchange reaction. This is highly plausible as in PDC the n-type electronic carriers are localized in the form of $\operatorname{Pr}_{\mathrm{Ce}}^{\prime}$ (in contrast to GDC where the n-type carriers $\mathrm{Ce}_{\mathrm{Ce}}^{\prime}$ are independent of the dopant). Consequently, the formation of charged molecular oxygen adsorbates in the fast proceeding equilibrium should be formulated as

$$
\begin{gathered}
\mathrm{O}_{2}+\mathrm{Pr}_{\mathrm{Ce}}^{\prime} \rightleftharpoons \mathrm{O}_{2}{ }^{-}+\mathrm{Pr}_{\mathrm{Ce}}^{\times} \\
\mathrm{O}_{2}{ }^{-}+\mathrm{Pr}_{\mathrm{Ce}}^{\prime} \rightleftharpoons \mathrm{O}_{2}{ }^{2-}+\mathrm{Pr}_{\mathrm{Ce}}^{\times}
\end{gathered}
$$

This means that the $\mathrm{O}_{2}{ }^{-}$and $\mathrm{O}_{2}{ }^{2-}$ adsorbate concentrations should scale with $\left(\operatorname{Pr}_{\mathrm{Ce}}^{\prime} / \operatorname{Pr}_{\mathrm{Ce}}^{\times}\right)$and $\left(\operatorname{Pr}_{\mathrm{Ce}}^{\prime} / \operatorname{Pr}_{\mathrm{Ce}}^{\times}\right)^{2}$. It is not easy to estimate whether this ratio (in the surface layer of the sample) exhibits a pronounced systematic variation with $[\mathrm{Pr}]_{\text {tot }}$. On the other hand, one may expect that because of the possible valence change, sites close to $\mathrm{Pr}^{3+/ 4+}$ are preferred adsorption sites for $\mathrm{O}_{2}{ }^{-}$and $\mathrm{O}_{2}{ }^{2-}$, which could result in adsorbate concentrations that systematically increase with $[\mathrm{Pr}]_{\text {tot }}$. This would then also increase the subsequent dissociation rate. Another aspect is that the character of the electronic defects changes drastically with $[\mathrm{Pr}]_{\text {tot }}$, from isolated $\mathrm{Pr}^{3+/ 4+}$ ions at low $[\mathrm{Pr}]_{\text {tot }}$ to praseodymium states forming an impurity band with non-vanishing band width at high $[\mathrm{Pr}]_{\mathrm{tot}}{ }^{69}$ This may lead to more negative adsorption energies for $\mathrm{O}_{2}{ }^{-}$and $\mathrm{O}_{2}{ }^{2-}$ and further increases the dependency of $\Re_{0}$ on [Pr]. The hypothesis of Pr band formation is supported by the strongly nonlinear increase of electronic conductivity (ESI Fig. $6, \dagger c f$. also $3 \times 10^{-5} \mathrm{~S} \mathrm{~cm}^{-1}$ for 1 PDC to $0.02 \mathrm{~S} \mathrm{~cm}^{-1}$ for 10PDC at $800{ }^{\circ} \mathrm{C}$ in air $^{18}$ ). At present, we cannot draw a final conclusion about the atomistic origin of the strong $[\mathrm{Pr}]_{\mathrm{tot}}$ dependence of $\Re_{0}$.

Another peculiarity of 6PDC and 20PDC (as well as of 6TDC and 20TDC) is that they show much lower formation of ${ }^{34} \mathrm{O}_{2}$ compared to 6GDC, 20GDC despite higher equilibrium exchange rates. This might point towards a higher $\mathrm{V}_{\mathrm{O}}^{*}$ mobility in bulk but also between bulk and surface layer. According to defect chemical data, $10 \mathrm{PDC}^{57}$ has a moderately higher $\mathrm{V}_{\mathrm{O}}^{*}$ mobility than single crystal $10 \mathrm{GDC}$ (measured by ${ }^{18} \mathrm{O}$ isotope exchange and SIMS line scan), ${ }^{7}$ which is in agreement with MD simulations. ${ }^{88}$ Nevertheless, this should be further confirmed in additional bulk diffusion measurements.

\section{Comparison to literature}

In Fig. 10a, tracer exchange coefficients $k^{*}$ obtained from literature for $10 \mathrm{GDC}$ to $31 \mathrm{GDC}^{7,8,11,15,16}$ are plotted versus temperature. Equilibrium exchange rates $\Re_{0}$ from the present study and from PIE measured by Yoo $^{16}$ are converted according to $k^{*}=\Re_{0}\left[\mathbf{O}_{\mathrm{O}}^{\times}\right]^{-1}$. The data from Yoo agree well with the present data, and both data sets connect reasonably well to isotope exchange line profile (IELP) results at lower $T$ (ref. 11) (which, however, exhibit a decreased activation energy). Exchange rates determined by IELP in ref. 7 and 8 and isotope exchange gas phase analysis (IEGA) ${ }^{15}$ are two to three orders of magnitude smaller but show similar slopes at temperatures above $500{ }^{\circ} \mathrm{C}$.

For PDC (Fig. 10b) the literature data scatter by almost six orders of magnitude. The present PIE data for 20PDC and isothermal isotope exchange (IIE) of the same 20PDC particles are of comparable magnitude. They are also similar to the
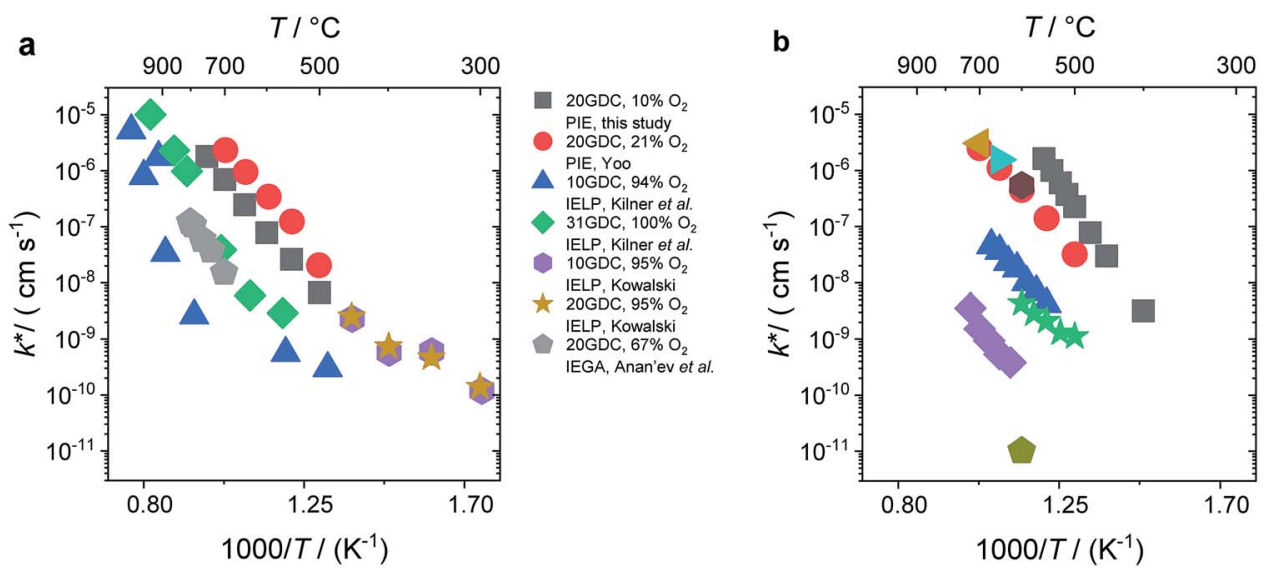

20PDC, $10 \% \mathrm{O}_{2}$

$\mathrm{PIE}$, this study

2OPDC, $10 \% \mathrm{O}_{2}$ IIE, this study 20PDC, $21 \% \mathrm{O}_{2}$ PIE, Yoo

10PDC, $21 \% \mathrm{O}_{2}$ EIS, Chen et al. 10PDC, $7 \% \mathrm{O}_{2}$ in situ strain, Ma et al. (2018) 10PDC, $7 \% \mathrm{O}_{2}$ in situ strain, Ma et al. (2017) 10PDC, $7 \% \mathrm{O}_{2}$ mass relaxation, Simons et al. $\mathrm{Pr}_{2} \mathrm{O}_{3}, 21 \% \mathrm{O}_{2}$ IELP, Nicollet et al. 10PDC, $21 \% \mathrm{O}_{2}$ optical absorption relaxation, Kim et al.

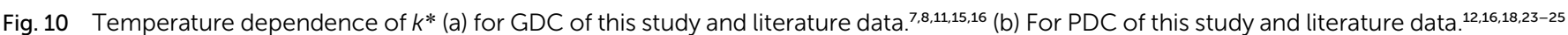
The values $k^{*}$ were calculated by $k^{*}=\Re_{0}\left[\mathrm{O}_{\mathrm{O}}^{\times}\right]^{-1}$. 
20PDC value of Yoo, to the exchange rate for 10PDC measured by mass relaxation of thin films deposited on a piezoelectric $\mathrm{GaPO}_{4}$ microbalance crystal ${ }^{23}$ (converted to $k^{*}$ using a mean thermodynamic factor of $\omega=200$, determined by TGA on 20PDC particles, $T$ range: $500-700{ }^{\circ} \mathrm{C}$ ), and to values for $\operatorname{Pr}_{6} \mathrm{O}_{11}$ from IELP. ${ }^{12}$ However, $k^{\mathrm{q}} \approx k^{*}$ values from impedance spectroscopy of 10PDC films on YSZ substrates ${ }^{18}$ have a similar activation energy, but are about two orders of magnitude lower. The smallest exchange rates were found by Ma et al. ${ }^{\mathbf{2 4 , 2 5}}$ by in situ strain measurements on 10PDC thin films on YSZ substrates and by Kim et $a .^{21}$ by in situ optical absorption relaxation.

This comparison demonstrates that the surface exchange rates are extremely sensitive to experimental details. Since in this study the ceramic samples were never exposed to $\mathrm{Ag}, \mathrm{Pt}$, or other precious metals which are known to catalyze the oxygen exchange reaction, such an effect is not the origin of the high equilibrium exchange rates. Bucher et al. ${ }^{89}$ demonstrated that $\mathrm{SiO}_{2}$ from any source in the experimental set-up such as quartz glass (in particular when the gas phase is not absolutely dry) can severely decrease the surface exchange rate of mixedconducting perovskites by formation of a thin glassy or silicate layer. Even stronger degradation by more than 1.5 orders or magnitude was found by Zhao et al. ${ }^{90}$ for 10PDC films, which might be related to the fact that ceria does not form silicates (nucleating only at specific sites), but instead silica probably homogeneously covers large parts of the surface.

\section{Conclusions}

For an extended set of ceria samples doped with Gd and Pr, the equilibrium oxygen exchange rate measured by pulsed isotope exchange correlates clearly with the dopant concentration. Together with the $p\left(\mathrm{O}_{2}\right)$ dependence, this can be interpreted for GDC with one oxygen vacancy being involved before or in the rate-determining step, and molecular oxygen species in the rds. For PDC an even stronger increase with dopant concentration is observed, accelerating $\Re_{0}$ at $700{ }^{\circ} \mathrm{C}$ by five orders of magnitude for 20PDC compared to undoped $\mathrm{CeO}_{2}$. This is assigned to the formation of a Pr impurity band, which may facilitate electron transfer to adsorbed oxygen species and thus increase adsorbate coverage. Its closely related defect chemical behavior and very similar increase of $\Re_{0}$ with $\mathrm{Tb}$ content indicate that the oxygen exchange reaction on Tb-doped ceria follows the same mechanism as for PDC. The observation that no ${ }^{34} \mathrm{O}_{2}$ is formed on samples with a high $\mathrm{Pr}$ or $\mathrm{Tb}$ content might be related to enhanced oxygen diffusivity. The fact that co-doping with $\mathrm{Nb}$ decreases $\Re_{0}$ to the values of undoped $\mathrm{CeO}_{2}$ supports the interpretation that the effect of doping is to a significant part due to the role of $\mathrm{V}_{\mathrm{O}}^{*}$ (with additional effects from electronic structure for Pr). The results impressively demonstrate the importance of point defects for surface reaction kinetics, with the highest rates achieved when $\mathrm{V}_{\mathrm{O}}^{*}$ as well as redox-active centers are available. Furthermore, one has to keep in mind that surface reaction rates are much more sensitive to experimental details (e.g., surface poisoning or catalytically active impurities) than bulk properties. The present study demonstrates the importance to investigate an extended set of systematically doped samples by the same method in order to obtain clear correlations.

\section{Conflicts of interest}

There are no conflicts to declare.

\section{Acknowledgements}

We thank H. Hoier for performing XRD, K. Müller for XPS measurements, W. Sigle for TEM/EDX analysis, and A. Fuchs for SEM imaging.

\section{References}

1 Z. Gao, L. V. Mogni, E. C. Miller, J. G. Railsback and S. A. Barnett, Energy Environ. Sci., 2016, 9, 1602-1644.

2 J. A. Kilner, Solid State Ionics, 2000, 129, 13-23.

3 J. Paier, C. Penschke and J. Sauer, Chem. Rev., 2013, 113, 3949-3985.

4 M. Melchionna and P. Fornasiero, Mater. Today, 2014, 17, 349-357.

5 R. J. Gorte, J. M. Vohs and S. McIntosh, Solid State Ionics, 2004, 175, 1-6.

6 A. Trovarelli, C. de Leitenburg, M. Boaro and G. Dolcetti, Catal. Today, 1999, 50, 353-367.

7 P. S. Manning, J. D. Sirman and J. A. Kilner, Solid State Ionics, 1996, 93, 125-132.

8 E. Ruiz-Trejo, J. D. Sirman, Y. M. Baikov and J. A. Kilner, Solid State Ionics, 1998, 113-115, 565-569.

9 J. A. Lane and J. A. Kilner, Solid State Ionics, 2000, 136, $927-$ 932.

10 J. Rutman, M. Kilo, S. Weber and I. Riess, Solid State Ionics, 2014, 265, 29-37.

11 K. Kowalski, Defect Diffus. Forum, 2009, 289-292, 769-774.

12 C. Nicollet, A. Flura, V. Vibhu, A. Rougier, J.-M. Bassat and J.-C. Grenier, Int. J. Hydrogen Energy, 2016, 41, 15538-15544.

13 K. Yashiro, T. Suzuki, A. Kaimai, H. Matsumoto, Y. Nigara, T. Kawada, J. Mizusaki, J. Sfeir and J. Van herle, Solid State Ionics, 2004, 175, 341-344.

14 E. N. Armstrong, K. L. Duncan, D. J. Oh, J. F. Weaver and E. D. Wachsman, J. Electrochem. Soc., 2011, 158, B492-B499.

15 M. V. Anan'ev, E. K. Kurumchin, G. K. Vdovin and N. M. Bershitskaya, Russ. J. Electrochem., 2012, 48, 871-878. 16 C.-Y. Yoo, PhD thesis, Universiteit Twente, Twente, The Netherlands, 2012.

17 M. Balaguer, C.-Y. Yoo, H. J. M. Bouwmeester and J. M. Serra, J. Mater. Chem. A, 2013, 1, 10234-10242.

18 D. Chen, S. R. Bishop and H. L. Tuller, J. Electroceram., 2012, 28, 62-69.

19 A. Karthikeyan and S. Ramanathan, Appl. Phys. Lett., 2008, 92, 243109.

20 S. R. Bishop, J. J. Kim, N. Thompson and H. L. Tuller, in Ionic and Mixed Conducting Ceramics 8, ed. M. B. Mogensen, T. M. Gur, X. D. Zhou, T. Armstrong and H. Yokokawa, Electrochemical Soc Inc, Pennington, 2012, vol. 45, pp. 491-495. 
21 J. J. Kim, S. R. Bishop, N. J. Thompson and H. L. Tuller, ECS Trans., 2013, 57, 1979-1984.

22 M. Katsuki, S. Wang, K. Yasumoto and M. Dokiya, Solid State Ionics, 2002, 154-155, 589-595.

23 P. Simons, H. I. Ji, T. C. Davenport and S. M. Haile, J. Am. Ceram. Soc., 2017, 100, 1161-1171.

24 Y. Ma and J. D. Nicholas, ECS Trans., 2017, 78, 395-403.

25 Y. Ma and J. D. Nicholas, Phys. Chem. Chem. Phys., 2018, 20, 27350-27360.

26 Y. M. Choi, H. Abernathy, H. T. Chen, M. C. Lin and M. L. Liu, ChemPhysChem, 2006, 7, 1957-1963.

27 M. Huang and S. Fabris, Phys. Rev. B: Condens. Matter Mater. Phys., 2007, 75, 4.

28 H.-T. Chen, J.-G. Chang, H.-L. Chen and S.-P. Ju, J. Comput. Chem., 2009, 30, 2433-2442.

29 Z. Wu, M. Li, J. Howe, H. M. Meyer and S. H. Overbury, Langmuir, 2010, 26, 16595-16606.

30 P. J. Gellings and H. J. M. Bouwmeester, Catal. Today, 2000, $58,1-53$.

31 J. Maier, Chem.-Eur. J., 2001, 7, 4762-4770.

32 R. Merkle and J. Maier, Top. Catal., 2006, 38, 141-145.

33 E. W. McFarland and H. Metiu, Chem. Rev., 2013, 113, 43914427.

34 N. Nilius and H.-J. Freund, Acc. Chem. Res., 2015, 48, 15321539.

35 G. Simkovich and C. Wagner, J. Catal., 1962, 1, 521-525.

36 P. Murugaraj and J. Maier, Solid State Ionics, 1989, 32-33, 993-999.

37 H. J. M. Bouwmeester, C. Song, J. Zhu, J. Yi, M. v. S. Annaland and B. A. Boukamp, Phys. Chem. Chem. Phys., 2009, 11, 96409643.

38 C.-Y. Yoo and H. J. M. Bouwmeester, Phys. Chem. Chem. Phys., 2012, 14, 11759-11765.

39 C.-Y. Yoo, B. A. Boukamp and H. J. M. Bouwmeester, J. Solid State Electrochem., 2011, 15, 231-236.

40 I. Riess, Solid State Ionics, 2015, 280, 51-65.

41 C.-Y. Yoo, B. A. Boukamp and H. J. M. Bouwmeester, Solid State Ionics, 2014, 262, 668-671.

42 S. R. Bishop, T. S. Stefanik and H. L. Tuller, Phys. Chem. Chem. Phys., 2011, 13, 10165-10173.

43 L. W. Tai and P. A. Lessing, J. Mater. Res., 1992, 7, 511-519. 44 L. W. Tai and P. A. Lessing, J. Mater. Res., 1992, 7, 502-510.

45 C. J. Powell and A. Jablonski, NIST electron effectiveattenuation-length database, Version 1.3, SRD 82, National Institute of Standards and Technology, Gaithersburg, 2011.

46 S. Saher, S. Naqash, B. A. Boukamp, B. Hu, C. Xia and H. J. M. Bouwmeester, J. Mater. Chem. A, 2017, 5, 4991-4999.

47 F. A. Kröger and H. J. Vink, in Solid State Physics, ed. F. Seitz and D. Turnbull, Academic Press, 1956, vol. 3, pp. 307-435.

48 H. L. Tuller and A. S. Nowick, J. Phys. Chem. Solids, 1977, 38, 859-867.

49 I. Riess, H. Janczikowski and J. Nölting, J. Appl. Phys., 1987, 61, 4931-4933.

50 B. Zachau-Christiansen, T. Jacobsen and S. Skaarup, Solid State Ionics, 1996, 86-88, 725-731.

$51 \mathrm{~S}$. Wang, H. Inaba, H. Tagawa and T. Hashimoto, J. Electrochem. Soc., 1997, 144, 4076-4080.
52 B. C. H. Steele, Solid State Ionics, 2000, 129, 95-110.

53 M. C. Göbel, G. Gregori and J. Maier, Solid State Ionics, 2012, 215, 45-51.

54 I. K. Naik and T. Y. Tien, J. Electrochem. Soc., 1979, 126, 562566.

55 T. Kolodiazhnyi, H. Sakurai, A. A. Belik and O. V. Gornostaeva, Acta Mater., 2016, 113, 116-123.

56 C. Chatzichristodoulou, P. V. Hendriksen and A. Hagen, J. Electrochem. Soc., 2010, 157, B299-B307.

57 S. R. Bishop, T. S. Stefanik and H. L. Tuller, J. Mater. Res., 2012, 27, 2009.

58 C. Chatzichristodoulou and P. V. Hendriksen, J. Electrochem. Soc., 2010, 157, B481-B489.

59 M. Nolan, S. Grigoleit, D. C. Sayle, S. C. Parker and G. W. Watson, Surf. Sci., 2005, 576, 217-229.

60 M. Nolan, J. E. Fearon and G. W. Watson, Solid State Ionics, 2006, 177, 3069-3074.

61 L. Yan, K. R. Balasubramaniam, S. Wang, H. Du and P. A. Salvador, Solid State Ionics, 2011, 194, 9-16.

62 L. Zhang, S. Wang, H. Huang, Y. Li, Y. Lu and C. Xia, J. Electrochem. Soc., 2017, 164, F610-F615.

63 O. Porat, H. L. Tuller, E. B. Lavik and Y. M. Chiang, in Nanophase and Nanocomposite Materials Ii, ed. S. Komarneni, J. C. Parker and H. J. Wollenberger, Materials Research Society, Warrendale, 1997, vol. 457, pp. 99-103.

64 P. Knauth and H. L. Tuller, J. Eur. Ceram. Soc., 1999, 19, 831836.

65 S. Kim, R. Merkle and J. Maier, Surf. Sci., 2004, 549, 196-202. 66 C. B. Gopal, F. E. Gabaly, A. H. McDaniel and W. C. Chueh, Adv. Mater., 2016, 28, 4692-4697.

67 W. C. Chueh, A. H. McDaniel, M. E. Grass, Y. Hao, N. Jabeen, Z. Liu, S. M. Haile, K. F. McCarty, H. Bluhm and F. El Gabaly, Chem. Mater., 2012, 24, 1876-1882.

68 Z. A. Feng, F. El Gabaly, X. Ye, Z.-X. Shen and W. C. Chueh, Nat. Commun., 2014, 5, 4374.

69 Q. Lu, G. Vardar, M. Jansen, S. R. Bishop, I. Waluyo, H. L. Tuller and B. Yildiz, Chem. Mater., 2018, 30, 2600-2606. 70 G. Zhou, P. R. Shah, T. Montini, P. Fornasiero and R. J. Gorte, Surf. Sci., 2007, 601, 2512-2519.

71 C. Balaji Gopal, M. García-Melchor, S. C. Lee, Y. Shi, A. Shavorskiy, M. Monti, Z. Guan, R. Sinclair, H. Bluhm, A. Vojvodic and W. C. Chueh, Nat. Commun., 2017, 8, 15360. 72 J. Maier, Solid State Ionics, 2000, 135, 575-588.

73 J. Maier, Solid State Ionics, 1998, 112, 197-228.

74 L. Vegard, Z. Phys., 1921, 5, 17-26.

75 R. D. Shannon, Acta Crystallogr., Sect. A: Cryst. Phys., Diffr., Theor. Gen. Crystallogr., 1976, 32, 751-767.

76 N. Knoblauch, L. Dorrer, P. Fielitz, M. Schmucker and G. Borchardt, Phys. Chem. Chem. Phys., 2015, 17, 5849-5860.

77 T. S. Zhang, J. Ma, H. Cheng and S. H. Chan, Mater. Res. Bull., 2006, 41, 563-568.

78 H. J. Avila-Paredes, K. Choi, C. T. Chen and S. Kim, J. Mater. Chem., 2009, 19, 4837-4842.

79 E. N. Armstrong, K. L. Duncan and E. D. Wachsman, Phys. Chem. Chem. Phys., 2013, 15, 2298-2308.

80 L. Wang, R. Merkle, Y. A. Mastrikov, E. A. Kotomin and J. Maier, J. Mater. Res., 2012, 27, 2000-2008. 
81 M. M. Kuklja, E. A. Kotomin, R. Merkle, Y. A. Mastrikov and J. Maier, Phys. Chem. Chem. Phys., 2013, 15, 5443-5471.

82 A. Rothschild, W. Menesklou, H. L. Tuller and E. Ivers-Tiffée, Chem. Mater., 2006, 18, 3651-3659.

83 V. Metlenko, W. Jung, S. R. Bishop, H. L. Tuller and R. A. De Souza, Phys. Chem. Chem. Phys., 2016, 18, 29495-29505.

84 A. Schmid, G. M. Rupp and J. Fleig, Chem. Mater., 2018, 30, 4242-4252.

85 C. Yang, X. Yu, S. Heißler, P. G. Weidler, A. Nefedov, Y. Wang, C. Wöll, T. Kropp, J. Paier and J. Sauer, Angew. Chem., Int. Ed., 2017, 56, 16399-16404.
86 Y. A. Mastrikov, R. Merkle, E. A. Kotomin, M. M. Kuklja and J. Maier, J. Mater. Chem. A, 2018, 6, 11929-11940.

87 Y. A. Mastrikov, R. Merkle, E. Heifets, E. A. Kotomin and J. Maier, J. Phys. Chem. C, 2010, 114, 3017-3027.

88 P. P. Dholabhai, J. B. Adams, P. A. Crozier and R. Sharma, J. Mater. Chem., 2011, 21, 18991-18997.

89 E. Bucher, W. Sitte, F. Klauser and E. Bertel, Solid State Ionics, 2011, 191, 61-67.

90 L. Zhao, N. H. Perry, T. Daio, K. Sasaki and S. R. Bishop, Chem. Mater., 2015, 27, 3065-3070. 